\title{
Evaluation of CMIP6 Models over Two Third Pole Subregions with Contrasting Circulation Systems $\mathbb{O}$
}

\author{
Ying Li, ${ }^{\mathrm{a}, \mathrm{b}}$ ChenghaO WANG, ${ }^{\mathrm{c}}$ AND FENGGE SU ${ }^{\mathrm{b}, \mathrm{d}, \mathrm{e}}$ \\ ${ }^{a}$ College of Hydraulic and Environmental Engineering, China Three Gorges University, Yichang, China \\ ${ }^{\mathrm{b}}$ State Key Laboratory of Tibetan Plateau Earth System, Resources and Environment (TPESRE), Institute of Tibetan Plateau Research, \\ Chinese Academy of Sciences (CAS), Beijing, China \\ ${ }^{\mathrm{c}}$ Department of Earth System Science, Stanford University, Stanford, California \\ ${ }^{\mathrm{d}}$ CAS Center for Excellence in Tibetan Plateau Earth Sciences, Beijing, China \\ ${ }^{\mathrm{e}}$ University of Chinese Academy of Sciences, Beijing, China
}

(Manuscript received 16 March 2021, in final form 24 August 2021)

\begin{abstract}
Reliable simulations of historical and future climate are critical to assessing ecological and hydrological responses over the Third Pole region (TP; the area including the Himalaya-Hindu Kush mountain range and the Tibetan Plateau). In this study, we evaluate the historical and future temperature and precipitation simulations of 18 models from phase 6 of the Coupled Model Intercomparison Project (CMIP6) in southeastern TP (SETP) and the upstream area of the Amu Darya and Syr Darya (UAS) regions, two typical TP subregions dominated by the Indian summer monsoon system and westerlies, respectively. Comparison against station observations suggests that CMIP6 models generally capture the intra-annual variability and spatial pattern of historical climate over both subregions. However, the wetting and cold biases observed in CMIP5 still persist in CMIP6; annual temperature is underestimated by most models and annual precipitation is overestimated by all models. Multimodel average cold biases in SETP and UAS are $1.18^{\circ}$ and $0.32^{\circ} \mathrm{C}$, respectively, and wet biases in SETP and UAS are $119 \%$ and $46 \%$, respectively. We further analyze climate projections under SSP1-2.6, SSP24.5, and SSP5-8.5 scenarios. Both SETP and UAS subregions are projected to experience significant warming in 2015-2100, with warming trends $34 \%-42 \%$ and $40 \%-50 \%$ higher than the global trend, respectively. Model projections suggest that the warming trend will slow down under SSP1-2.6 and SSP2-4.5 but further intensify under SSP5-8.5 in 2050-2100. Monsoondominated SETP is projected to experience a significant wetting trend stronger than UAS over the entire future period, especially in summer (cf. winter in westerlies-dominated UAS). Concurrently, a significant drying trend in summer is found in UAS during 2050-2100 under SSP5-8.5, suggesting the intensified uneven distributions of seasonal precipitation based on projections.
\end{abstract}

KEYWORDS: Atmospheric circulation; Precipitation; Climate change; Temperature; Bias; Climate prediction; Ensembles; Model evaluation/performance

\section{Introduction}

The Third Pole (TP), which contains the largest reserve of ice outside the polar regions, is a high-altitude region spanning the Himalaya-Hindu Kush mountain range and the Tibetan Plateau in Afghanistan, Bangladesh, Bhutan, China, India, Myanmar, Nepal, and Pakistan (Yao et al. 2017, 2019). As an important component of the global hydrological cycle $(\mathrm{Wu}$ et al. 2015), this region is the source of 10 major Asian rivers that provide water for over one-fifth of the world's population and is known as the water tower of Asia (Immerzeel et al. 2010). Since the early 1950s, the TP region has undergone significant warming with a rate ranging from $0.16^{\circ}$ to $0.67^{\circ} \mathrm{C}$ $(10 \mathrm{yr})^{-1}$ during different periods, about 2 times higher than that of the global mean (Chen et al. 2015; Kuang and Jiao 2016). Meanwhile, strong cryospheric melt and an intensified water cycle have been observed, accompanied by severe water

Supplemental information related to this paper is available at the Journals Online website: https://doi.org/10.1175/JCLI-D-210214.s1.

Corresponding author: Fengge Su, fgsu@itpcas.ac.cn crises and an increasing frequency of hazards (Yao et al. 2012; Chen et al. 2015; Yao et al. 2019). Given its role in global atmospheric circulation and regional food and water security as well as its sensitivity to global warming, the TP region has gained increasing attention worldwide (Xu et al. 2008; Harris 2010; Jacob et al. 2012; Yao et al. 2012; Joswiak et al. 2013; Yao et al. 2013).

The climate of the TP region, especially the seasonal precipitation, is largely influenced by two contrasting atmospheric circulation systems: the Indian summer monsoon system and midlatitude westerlies. The warm and wet Indian monsoon system brings moisture from the Indian Ocean to the southwestern TP region in summer, whereas the relatively dry and cold westerlies mainly influence the central-western TP region and are affected by the seasonal migration of the intertropical convergence zone (Dimri et al. 2015; Curio and Scherer 2016; Singh et al. 2019). The varying spatial extents of these two systems result in contrasting subregional climate patterns, water and energy cycles, and responses to global climate change (Yang et al. 2014; Forsythe et al. 2015; Kumar et al. 2021). For example, differences in the response of glaciers to climate change, as induced by distinct precipitation trends and atmospheric circulation patterns, have been observed among subregions of the TP: the glaciers in eastern Pamir (a subregion 
mainly influenced by the westerlies) experienced the least amount of shrinkage, while those in the Himalayas (dominated by the Indian monsoon system) underwent the most intensive retreat in recent decades (Yao et al. 2012).

Large-scale assessments and predictions of historical and future climate change as well as its impacts in the TP region primarily leverage results of model simulations, especially those from the Coupled Model Intercomparison Project (CMIP). The CMIP, initiated by the World Climate Research Programme (WCRP), provides high-quality climate predictions for better understanding of past, present, and future climate change at both regional and global scales (Eyring et al. 2016), and serves as the foundation of the Intergovernmental Panel on Climate Change (IPCC) Assessment Reports and national climate scenarios (IPCC 2014; Pihl et al. 2019). Specifically, climate projections from phase 5 of CMIP (CMIP5) under different representative concentration pathways (RCPs) have been widely used to evaluate regional responses to future climate change in the twenty-first century over the TP region, including changes in elevation-dependent warming (Guo et al. 2016; Palazzi et al. 2017), permafrost active layer thickness (Zhao and Wu 2019), snow depth (Wei and Dong 2015), atmospheric water fluxes (Zhang et al. 2019), carbon fluxes from alpine grassland (Han et al. 2019), and climate extremes (Peng et al. 2020). Special attention has been paid to the predictions of hydrological changes (e.g., runoff changes) in the upstream of major Asian rivers using glaciohydrological models forced by CMIP results, given the strong influence of climate change on regional water availability (Lutz et al. 2014; Su et al. 2016; Zhao et al. 2019).

Trustworthy assessments based on CMIP models hinge on reliable historical simulations. However, biases in historical simulations of CMIP5 models and strong intermodel variabilities have been found in many regions around the world (including the TP region), even though the multimodel ensemble mean in general seems to capture the spatiotemporal characteristics of key climate variables (Rupp et al. 2013; Chen and Frauenfeld 2014; Koutroulis et al. 2016; Raghavan et al. 2018). In particular, based on the outputs of 24 global climate models (GCMs) from CMIP5 over the eastern TP region, Su et al. (2013) found that most models reasonably reproduced the spatial and temporal variations of historical precipitation and temperature, but clear cold and wet biases still existed. Similar biases over the TP region have been observed in later studies (Chen and Frauenfeld 2014; Chen et al. 2017; Palazzi et al. 2015). These biases are partly attributable to the coarse model resolution and the difficulty of reproducing some physical processes (e.g., land-atmosphere interactions and their response to the interplay of westerlies and the Indian monsoon system) over the high-altitude TP region with complex topography (Chen et al. 2017; Lin et al. 2018).

Building upon previous phases of CMIP, the experimental design of CMIP6 started in 2013. In particular, the longstanding problems of poorly quantified radiative forcing from different external forcing factors and systematic model biases in CMIP5 (and its predecessors) have been revisited with increased attention and new approaches in CMIP6 (Eyring et al. 2016; Stouffer et al. 2017). CMIP6 experiments are designed based on a broad community survey and focus strongly on specific scientific questions to better serve as the resource for the IPCC assessment reports and numerous national assessments (IPCC 2013; Gidden et al. 2019; Pascoe et al. 2020). Different from previous CMIP efforts, the climate projections in CMIP6 are driven by alternative scenarios of emissions and land use changes based on the combinations of Shared Socioeconomic Pathways (SSPs) and forcing pathways (RCPs) (O'Neill et al. 2016). Compared to the CMIP5 forcing, the CMIP6 forcing enables realistic quasi-biennial oscillation variability, as suggested by decadal hindcast simulations (Pohlmann et al. 2019). In addition, the CMIP6 models showed significant improvements in simulating the characteristics of some complex climate systems, including the Indian summer monsoon system (Gusain et al. 2020).

New results from CMIP6 have enabled the evaluation of historical and future climate simulations over the TP region. Recent studies have confirmed that CMIP6 models are able to reproduce some key regional circulation patterns in this region reasonably well. For example, Shang et al. (2021) found that more than half of the analyzed 18 CMIP6 models successfully reproduced the south-north dipole pattern of the Tibetan summer precipitation driven by a Rossby wave. Wang et al. (2019) demonstrated that in general, the ensemble mean of 12 CMIP6 models captured the seasonal peaks and a historical turning point of surface sensible heating (a determinant of the Asian summer monsoon) over the central and eastern Tibetan Plateau. Compared to relatively reliable simulations of circulation patterns, biases in historical simulations of temperature and precipitation still have been observed in most parts of the TP region. For example, a recent study by Zhu and Yang (2020) evaluated the historical simulations of CMIP6 models based on a gridded observational dataset (CN05.1, an interpolated dataset from national observation stations in China) over the Tibetan Plateau, and found systematic cold and wet biases as observed in CMIP5 (Su et al. 2013). Similar wet bias in CMIP6 was found over parts of arid Central Asia (especially southern Xinjiang and Hexi Corridor, including the northwestern edge of the TP region) in a study based on the Climate Research Unit (CRU) TS 4.04 precipitation datasets (Guo et al. 2021).

It is noteworthy that most evaluation studies are based on the interpolated observational datasets that cover several TP subregions with extremely low station density (e.g., the western Tibetan Plateau), which may introduce large uncertainties in evaluations over the entire TP region. On the other hand, the reliability of CMIP6 models over the TP region largely depends on whether models can reproduce the impacts of the Indian summer monsoon system and midlatitude westerlies. However, the performance of CMIP6 models in TP's subregions dominated by these two circulation systems still remains unexplored. In this study, we aim to fill these research gaps by systematically evaluating historical and future simulations of temperature and precipitation from 18 CMIP6 models in two typical TP subregions: the southeastern TP area (SETP) and the upstream area of the Amu Darya and Syr Darya in the Aral Sea basin (UAS). These two subregions are selected because 1) SETP is largely dominated by the Indian summer monsoon 
system, while UAS is dominated by westerlies all year around; 2) both subregions are covered by relatively dense station networks that facilitate more reliable model evaluations; and 3) both subregions contain headwaters of major rivers, and their responses to climate change are critical to water security of downstream regions.

The basic information of the selected two subregions is described in section 2. Data sources and methods are detailed in section 3. Specifically, the historical temperature and precipitation datasets are based on densely distributed station observations. We evaluate the performance of CMIP6 models in reproducing historical temperature and precipitation in SETP and UAS at different temporal scales in section 4 . We then analyze the projected climate changes in these representative subregions in the twenty-first century under three scenarios in section 5. In section 6 , we compare historical simulations of CMIP6 against those of CMIP5, and discuss the potential causes of biases in CMIP6 results. Section 7 concludes the study with implications for regional water resource planning and climate risk management.

\section{Study areas}

The two representative subregions selected in this study, SETP and UAS, are sources of several major rivers in Asia (Fig. 1). The monsoon-dominated SETP contains headwaters of the Yellow River, Yangtze River, Mekong River, and Salween River, and covers much of the Upper Brahmaputra in the southern Tibetan Plateau. The precipitation in SETP mainly occurs in the monsoon season, and the seasonal patterns of precipitation and temperature jointly determine the streamflow regime in this subregion (Cuo et al. 2014). As the source of many major rivers, SETP is critical to water resources and socioeconomic activities in mainland East and Southeast Asia. In this study, the boundary of SETP is defined by the $2000-\mathrm{m}$ contour line and a division line running from southwest to northeast. Note that the division line used to delineate SETP excludes regions with sparse weather stations to ensure high station density, which can largely reduce uncertainties induced by spatial interpolation (see Fig. 1 and section 3). The total area of SETP is $1595244 \mathrm{~km}^{2}$, and $\sim 1.1 \%$ is covered by glaciers $\left(17816 \mathrm{~km}^{2}\right.$ ) (RGI Consortium 2017).

The westerlies-dominated UAS contains headwaters of the Amu Darya and Syr Darya. These two rivers play a vital role in the water security and crop production of Central Asia and provide nearly all water supply for the Aral Sea (Micklin 2016). In the past several decades, the downstream of UAS has undergone severe environmental problems including not only water scarcity, soil pollution, and salinization, but also the dramatic retreat of the Aral Sea (Sorg et al. 2014; White et al. 2014). Reliable climate simulations over this headwater region are extremely important for downstream regional water resource planning and management. Here the boundary of UAS is defined by the upstream basins of the Amu Darya and Syr Darya, with outlets at Kerki and Chardara, respectively. The total area of UAS is $485101 \mathrm{~km}^{2}$, and $\sim 2.4 \%$ is covered by glaciers $\left(11649 \mathrm{~km}^{2}\right)$ (RGI Consortium 2017).

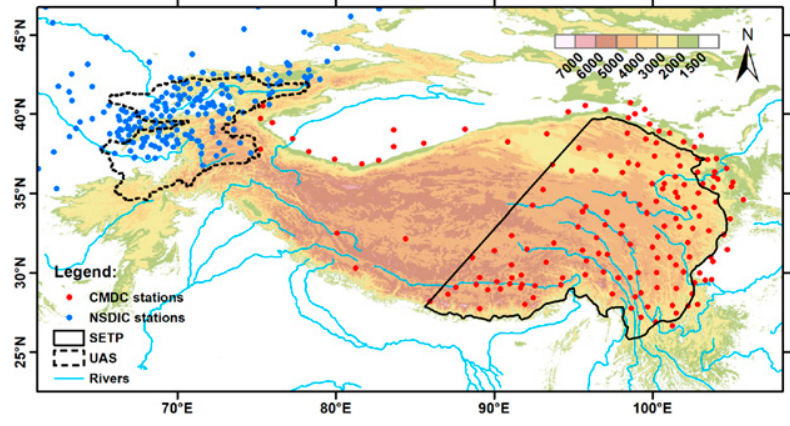

FIG. 1. Topography of the Third Pole (TP) region, with locations of meteorological stations from CMDC and NSIDC in red and blue, respectively. The boundaries of the study areas, the southeastern Tibetan Plateau (SETP) and the upstream areas of the Amu Darya and Syr Darya (UAS), are shown by a solid black line and a dashed black line, respectively.

\section{Data sources and methodology}

Both SETP and UAS are covered by densely distributed stations with continuous temperature and precipitation observations. Here we retrieved temperature and precipitation data from the China Meteorological Data Service Center (CMDC; http://data.cma.cn/) and the Central Asia Temperature and Precipitation Data archived in the National Snow and Ice Data Center (NSIDC; https://nsidc.org/data/g02174). The locations of meteorological stations from CMDC and NSIDC are shown in red and blue, respectively, in Fig. 1. There are 106 stations in SETP with monthly surface air temperature and precipitation data available from 1961 to 2014, and 111 stations in UAS with data from 1961 to 1990 (Williams and Konovalov 2008; Su et al. 2013). We retrieved temperature and precipitation observations from all available 217 stations over the selected two subregions to construct observational datasets, despite the differences in record length and number of stations. To facilitate the comparison with gridded CMIP6 model outputs, temperature and precipitation observations were interpolated to $0.5^{\circ} \times 0.5^{\circ}$ grids over SETP and UAS using linear barycentric interpolation on triangles. Note that here we selected a spatial resolution of $0.5^{\circ} \times 0.5^{\circ}$ because 1 ) this is close to the finest resolution of the evaluated CMIP6 models, 2) a finer resolution (as compared to, e.g., $1^{\circ} \times 1^{\circ}$ ) can more reasonably resolve the boundaries of SETP and UAS, and 3 ) a finer resolution can retain more information from the station observations (especially for UAS). A commonly used lapse rate of $6.5^{\circ} \mathrm{C}(1000 \mathrm{~m})^{-1}$ was adopted during the interpolation of temperature data to take into account temperature change with elevation ( $\mathrm{Li}$ et al. 2013). We further examined the influence of different spatial interpolation methods (linear barycentric interpolation, cubic spline interpolation, and inverse distance weighted interpolation) and spatial resolutions $\left(0.5^{\circ} \times 0.5^{\circ}\right.$ and $\left.1^{\circ} \times 1^{\circ}\right)$ on regional means and model evaluation; the method and results of this sensitivity analysis are summarized in the online supplemental material.

The CMIP6 historical (1850-2014) and future (2015-2100) simulations of temperature and precipitation were retrieved 
TABLE 1. Information on the 18 CMIP6 models used in this study. (Expansions of acronyms are available online at http://www.ametsoc.org/PubsAcronymList.)

\begin{tabular}{|c|c|c|c|}
\hline Model name & Center & Spatial resolution $(\mathrm{km})$ & Variant \\
\hline BCC-CSM2-MR & Beijing Climate Center, China & 100 & r1i1p1f1 \\
\hline BCC-ESM1 & & 250 & r1i1p1f1 \\
\hline CAMS-CSM1-0 & Chinese Academy of Meteorological Sciences, China & 100 & r1i1p1f1 \\
\hline CanESM5 & Canadian Centre for Climate Modeling and Analysis, Canada & 500 & r1i1p1f1 \\
\hline CESM2 & Community Earth System Model contributors, United States & 100 & r1i1p1f1 \\
\hline CESM2-WACCM & & 100 & r1i1p1f1 \\
\hline CNRM-CM6-1 & Centre National de Recherches Meteorologiques, France & 250 & r1i1p1f2 \\
\hline CNRM-ESM2-1 & & 250 & r1i1p1f2 \\
\hline EC-Earth3 & EC-Earth-Consortium, Europe-wide consortium & 50 & r1i1p1f1 \\
\hline EC-Earth3-Veg & & 100 & r1i1p1f1 \\
\hline GISS-E2-1-G & NASA's Goddard Institute for Space Studies, United States & 250 & r1i1p1f1 \\
\hline GISS-E2-1-H & & 250 & r1i1p1f1 \\
\hline HadGEM3-GC31-LL & Met Office Hadley Center, United Kingdom & 250 & r1i1p1f3 \\
\hline IPSL-CM6A-LR & Institut Pierre Simon Laplace, France & 250 & r1i1p1f1 \\
\hline MIROC6 & $\begin{array}{l}\text { Center for Climate System Research, University of Tokyo, Japan Agency } \\
\text { for Marine-Earth Science and Technology, and National Institute for } \\
\text { Environmental Studies, Japan }\end{array}$ & 250 & r1i1p1f1 \\
\hline MRI-ESM2-0 & Meteorological Research Institute, Japan & 100 & r1i1p1f1 \\
\hline SAM0-UNICON & Seoul National University, South Korea & 100 & r1i1p1f1 \\
\hline UKESM1-0-LL & $\begin{array}{l}\text { Met Office, NERC research centers, and U.K. academic institutions, } \\
\text { United Kingdom }\end{array}$ & 250 & r1i1p1f2 \\
\hline
\end{tabular}

from the Earth System Grid Federation website (https://esgfnode.llnl.gov/projects/cmip6). Table 1 summarizes basic information of the selected 18 CMIP6 models. All 18 models have historical experiments, which are all-forcing simulations of the recent past that are largely based on observations (Pascoe et al. 2020). For future climate projections, we select three scenarios, SSP1-2.6, SSP2-4.5, and SSP5-8.5, which represent a stringent mitigation scenario, an intermediate scenario, and a high emission scenario with radiative forcing levels reaching 2.6, 4.5 , and $8.5 \mathrm{~W} \mathrm{~m}^{-2}$ in 2100 , respectively. More specifically, SSP1 represents a sustainable scenario with low challenges to mitigation and adaptation, SSP2 represents a middle-of-the-road scenario with medium challenges to mitigation and adaptation, and SSP5 represents a fossil-fueled scenario with high challenges to mitigation but low challenges to adaptation (Riahi et al. 2017). We retrieved future projections of 12 models available at the time of our investigation (BCC-CSM2-MR, CAMS-CSM1-0, CanESM5, CESM2, CNRM-CM6-1, CNRM-ESM2-1, ECEarth3, EC-Earth3-Veg, IPSL-CM6A-LR, MIROC6, MRIESM2-0, UKESM1-0-LL). All the monthly temperature and precipitation fields from CMIP6 models were resampled to a spatial resolution of $0.5^{\circ} \times 0.5^{\circ}$ using bilinear interpolation. In the sensitivity analysis of different spatial resolutions, we also resampled CMIP6 model outputs to $1^{\circ} \times 1^{\circ}$ for comparison (see the online supplemental material).

We use bias (BIAS), relative bias (RBIAS), and the Pearson correlation coefficient $(r)$ to evaluate the performance of CMIP6 models. Their definitions are as follows:

$$
\begin{aligned}
\text { BIAS } & =\bar{S}-\bar{O}, \\
\text { RBIAS } & =\frac{\text { BIAS }}{\bar{O}} \times 100 \%,
\end{aligned}
$$

$$
r=\frac{\sum_{i=1}^{n}\left(S_{i}-\bar{S}\right)\left(O_{i}-\bar{O}\right)}{\sqrt{\sum_{i=1}^{n}\left(S_{i}-\bar{S}\right)^{2}} \sqrt{\sum_{i=1}^{n}\left(O_{i}-\bar{O}\right)^{2}}}
$$

where $S_{i}$ and $O_{i}$ represent simulated and observed temperature or precipitation data, respectively, $\bar{S}$ and $\bar{O}$ are the corresponding long-term mean values, and $n$ is the number of observation and simulation pairs. The values of BIAS (RBIAS) from historical evaluations of temperature (precipitation) are used to bias correct future climate simulations to improve their reliability.

\section{Evaluation of CMIP6 models for historical climate simulations}

In this section, we evaluate the performance of 18 CMIP6 models in reproducing historical temperature and precipitation in the selected two representative subregions (SETP and UAS). Simulated annual means, monthly and seasonal variations, and spatial patterns of historical temperature and precipitation are compared against observations in sections $4 \mathrm{a}$ and $4 b$. In section $4 c$, we further evaluate the trends of historical annual temperature and precipitation in simulations and observations.

\section{a. Historical temperature}

We first evaluate the performance of 18 CMIP6 models in reproducing the historical mean annual temperature averaged over Indian-monsoon-dominated SETP (1961-2014) and westerlies-dominated UAS (1961-90). Results of BIAS and $r$ are shown in Fig. 2. The observed long-term mean annual temperature values are $0.02^{\circ}$ and $4.62^{\circ} \mathrm{C}$ in SETP and UAS, 

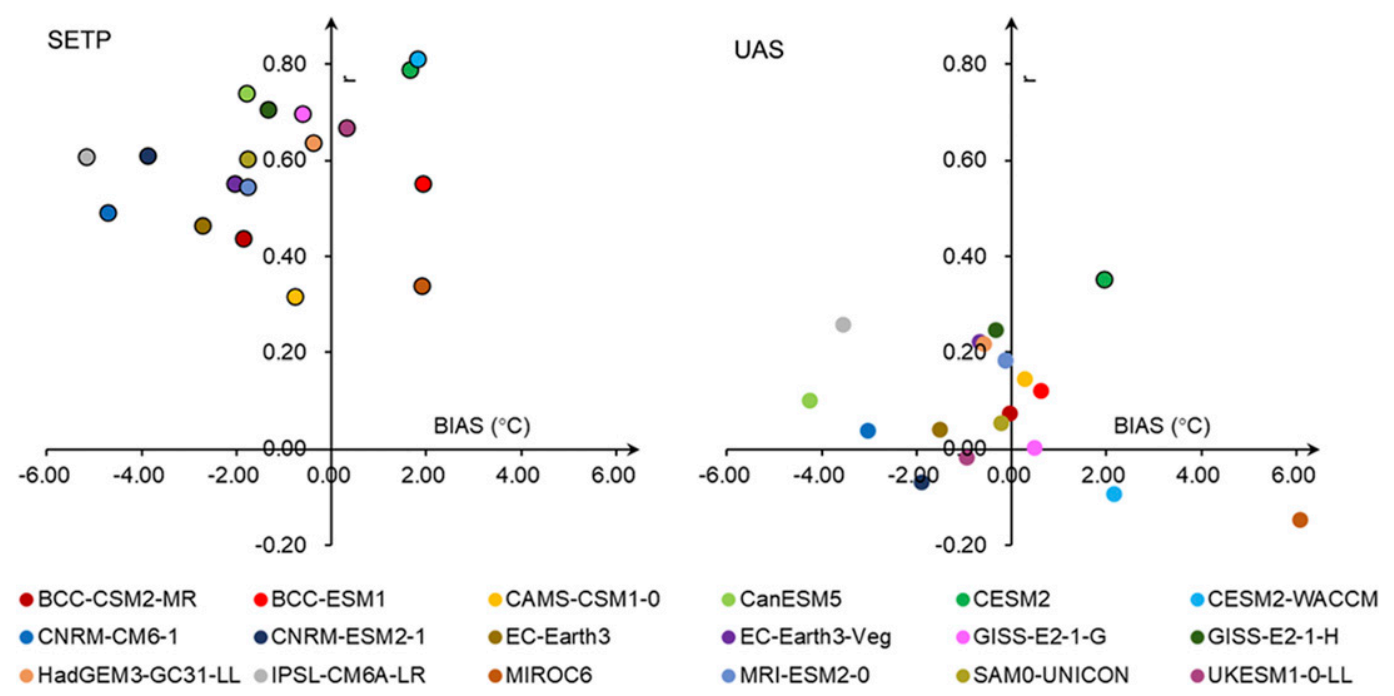

FIG. 2. BIAS and correlation coefficient $(r)$ of historical annual temperature predicted by 18 CMIP6 models when evaluated against observations for (left) SETP (1961-2014) and (right) UAS (1961-90). Points with black edges denote models with statistically significant $r$ values $(p<0.05)$.

respectively. However, 13 of the 18 CMIP6 models underestimate annual temperature in SETP (cold bias). Similar cold bias over UAS is observed in 12 models. For the multimodel averages of annual temperature, the cold bias in UAS is $0.32^{\circ} \mathrm{C}$ (cf. $1.18^{\circ} \mathrm{C}$ in SETP), suggesting a slightly better performance of the CMIP6 ensemble in reproducing long-term mean annual temperature in this westerlies-dominated subregion. In addition, the cold bias among CMIP6 models over SETP is close to that of CMIP5 models observed in previous studies, despite the differences in observational datasets and the spatial extent of the study area. For example, based on interpolated $2^{\circ} \times 2^{\circ}$ station observations in 1961-2005, Su et al. (2013) found a cold bias of $1.27^{\circ} \mathrm{C}$ over the eastern Tibetan Plateau for the ensemble mean of 24 CMIP5 models. Zhu and Yang (2020) observed a mean cold bias of $1.52^{\circ} \mathrm{C}$ over the entire Tibetan Plateau for 40 CMIP5 models when compared to a gridded observational dataset $\left(0.5^{\circ} \times 0.5^{\circ}\right)$ for the same period. The similarity suggests that the improvement of long-term mean annual temperature predictions in CMIP6 is relatively marginal over the Tibetan Plateau. Based on absolute values of BIAS, we then rank the performance of 18 CMIP6 models in reproducing long-term mean annual temperature (Fig. 3). The two best performing models for long-term mean annual temperature are UKESM1-0-LL (BIAS: $0.32^{\circ} \mathrm{C}$ ) and HadGEM3GC31-LL $\left(-0.39^{\circ} \mathrm{C}\right)$ in SETP, and BCC-CSM2-MR $\left(-0.04^{\circ} \mathrm{C}\right)$ and MRI-ESM2-0 $\left(-0.15^{\circ} \mathrm{C}\right)$ in UAS.

Significant correlations $(p<0.05)$ for the time series of historical mean annual temperature between simulations and observations are found in all 18 CMIP6 models over SETP, with all correlation coefficients greater than zero (Fig. 2). The correlation coefficients for historical annual temperature range from 0.32 to 0.81 in SETP. However, the correlations are
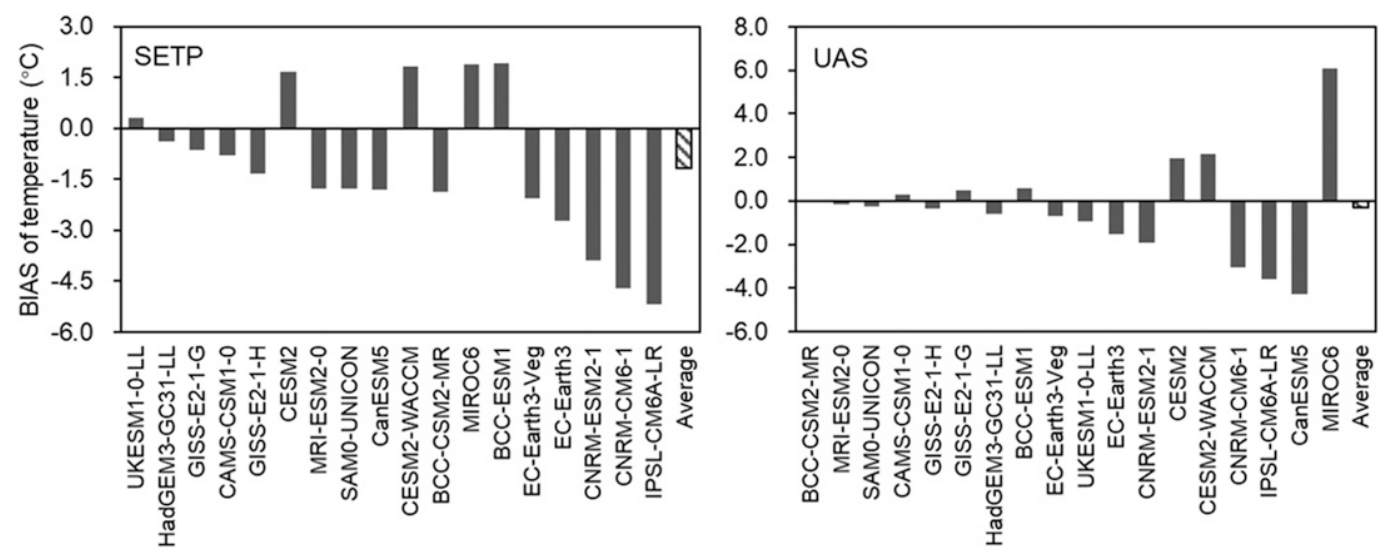

FIG. 3. The performance of 18 CMIP6 models in predicting long-term mean annual temperature ranked based on absolute values of BIAS for (left) SETP (1961-2014) and (right) UAS (1961-90). The hatched bar denotes BIAS of the multimodel average. 

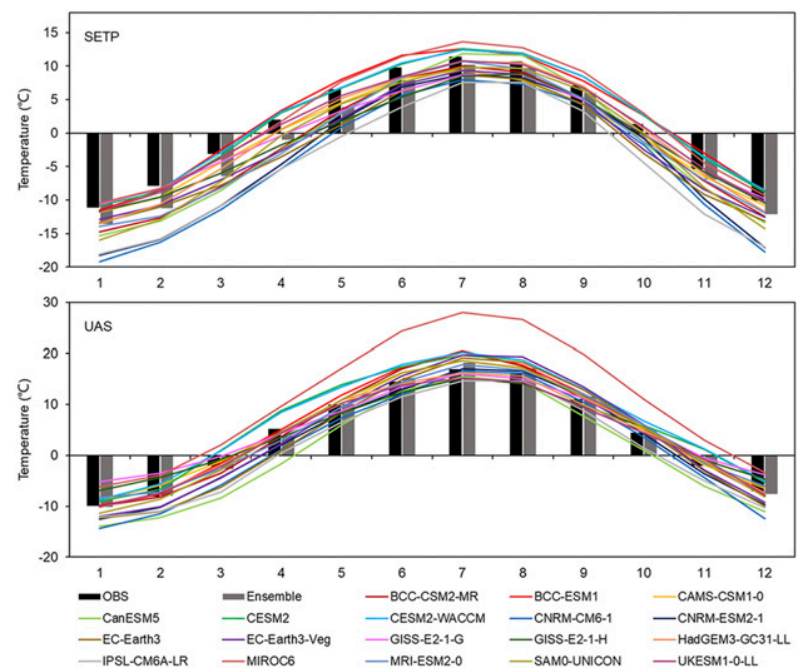

FIG. 4. Long-term mean monthly temperature based on 18 CMIP6 models and observations in SETP (1961-2014) and UAS (1961-90). The black bar denotes observations (OBS), and the gray bar denotes the multimodel ensemble mean.

relatively weak in UAS. Only one model (CESM2) shows significant correlation between predictions and observations $(p<0.05)$, while four models even have negative correlation coefficients (MIROC6, CESM2-WACCM, CNRM-ESM2-1, and UKESM1-0-LL). This suggests that, for interannual variability of temperature, CMIP6 models in general perform better in monsoon-dominated SETP than in UAS.

We then evaluate the monthly variations of historical temperature predictions from CMIP6 models against observations in SETP and UAS, as shown in Fig. 4. Most models successfully capture the temporal variation of monthly temperature over the TP region, despite one model (MIROC6) that significantly overestimates summer (June-August) temperature by $10.08^{\circ} \mathrm{C}$ in UAS. Similar to the results of long-term mean annual temperature, the multimodel ensemble mean more closely resembles monthly temperature observations in westerlies-dominated UAS than in SETP. Figure 5 shows seasonal values of BIAS for temperature over these two subregions. The BIAS values of seasonal multimodel average are: $-1.94^{\circ} \mathrm{C}$ (spring, MarchMay), $-0.12^{\circ} \mathrm{C}$ (summer, June-August), $-0.61^{\circ} \mathrm{C}$ (autumn, September-November), and $-2.05^{\circ} \mathrm{C}$ (winter, DecemberFebruary) in SETP, and $-1.19^{\circ}, 0.62^{\circ}, 0.04^{\circ}$, and $-0.76^{\circ} \mathrm{C}$ in UAS. Although the BIAS varies among CMIP6 models as well as among different seasons, relatively greater values of negative BIAS are observed in most models during spring and winter seasons, especially over monsoon-dominated SETP. In particular, the stronger cold biases in cold seasons over SETP are in line with CMIP5 results previously observed in the Tibetan Plateau (Su et al. 2013; Chen et al. 2017).

Based upon seasonal BIAS values for temperature, the two best performing models for SETP are UKESM1-0-LL (seasonal BIAS values are $0.35^{\circ}, 0.42^{\circ}, 0.58^{\circ}$, and $-0.05^{\circ} \mathrm{C}$ ) and HadGEM3-GC31-LL (seasonal BIAS values are $-0.58^{\circ}, 0.43^{\circ}$, $0.27^{\circ}$, and $-1.70^{\circ} \mathrm{C}$ ), while those for UAS are CAMS-CSM1-0

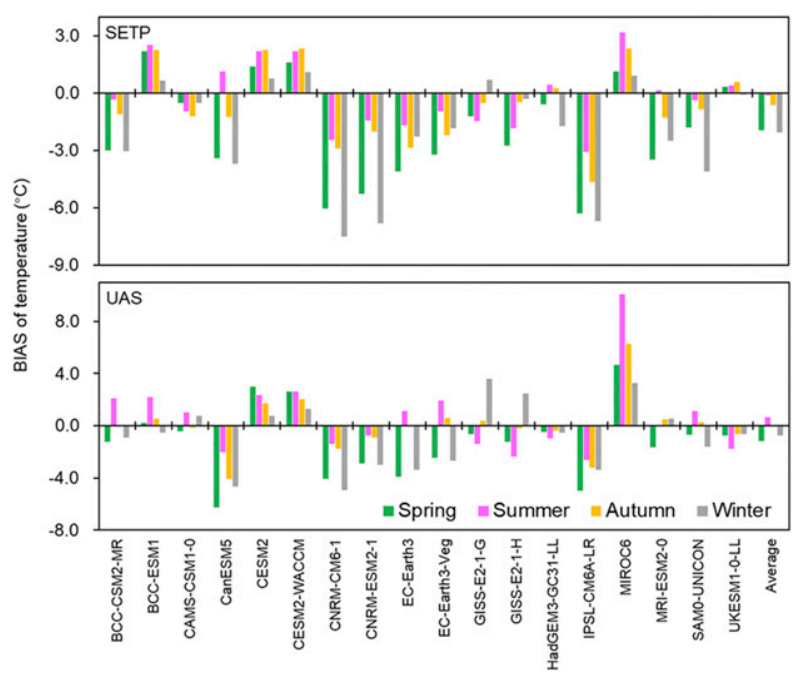

FIG. 5. BIAS of long-term mean seasonal temperature predicted by 18 CMIP6 models and the multimodel average when evaluated against observations for (top) SETP (1961-2014) and (bottom) UAS (1961-90).

(seasonal BIAS values are $-0.42^{\circ}, 0.99^{\circ},-0.18^{\circ}$, and $0.72^{\circ} \mathrm{C}$ from spring to winter) and HadGEM3-GC31-LL (seasonal BIAS values are $-0.47^{\circ},-0.94^{\circ},-0.39^{\circ}$, and $-0.57^{\circ} \mathrm{C}$ ). In cold seasons (spring and winter), cold bias persists as a significant deficiency for most CMIP6 models in both subregions, and the multimodel mean cold bias over monsoon-dominated SETP is about twice that over westerlies-dominated UAS. In addition, as shown in the sensitivity analysis (see the online supplemental material), although different interpolation methods and spatial resolutions may alter the direction of temperature biases for models with biases close to zero, in general, the results of temperature-related assessments are relatively insensitive to different processing methods.

We further evaluate the spatial pattern of long-term mean annual temperature predicted by CMIP6 models (Fig. 6). As suggested in all CMIP6 projections, areas with relatively lower temperature $\left(<-5^{\circ} \mathrm{C}\right)$ are mainly distributed within the TP region where the elevation is on average above $4000 \mathrm{~m}$. Areas with relatively higher $\left(>20^{\circ} \mathrm{C}\right)$ temperature are mostly in the low-altitude areas south of the Tibetan Plateau's southwestern edge. For ground-based observations in the two typical subregions, the mean annual temperature in SETP gradually increases from northwest to southeast, while in UAS it gradually increases from the Pamirs to the western plains, generally consistent with the elevation gradient. The pixel-to-pixel correlations between the simulated field of mean annual temperature and the interpolated field from observations are shown in Table A1 in the appendix. For temperature there is a good spatial agreement between simulations and observations in both subregions: the correlation coefficients of spatial patterns range from 0.60 to 0.79 for SETP (number of grids/pixels $N=$ $521, p<0.05)$ and from 0.74 to 0.89 for UAS $(N=120, p<$ $0.05)$. Nevertheless, when compared to station observations, a clear cold bias consistently exists in all 18 CMIP6 models along 

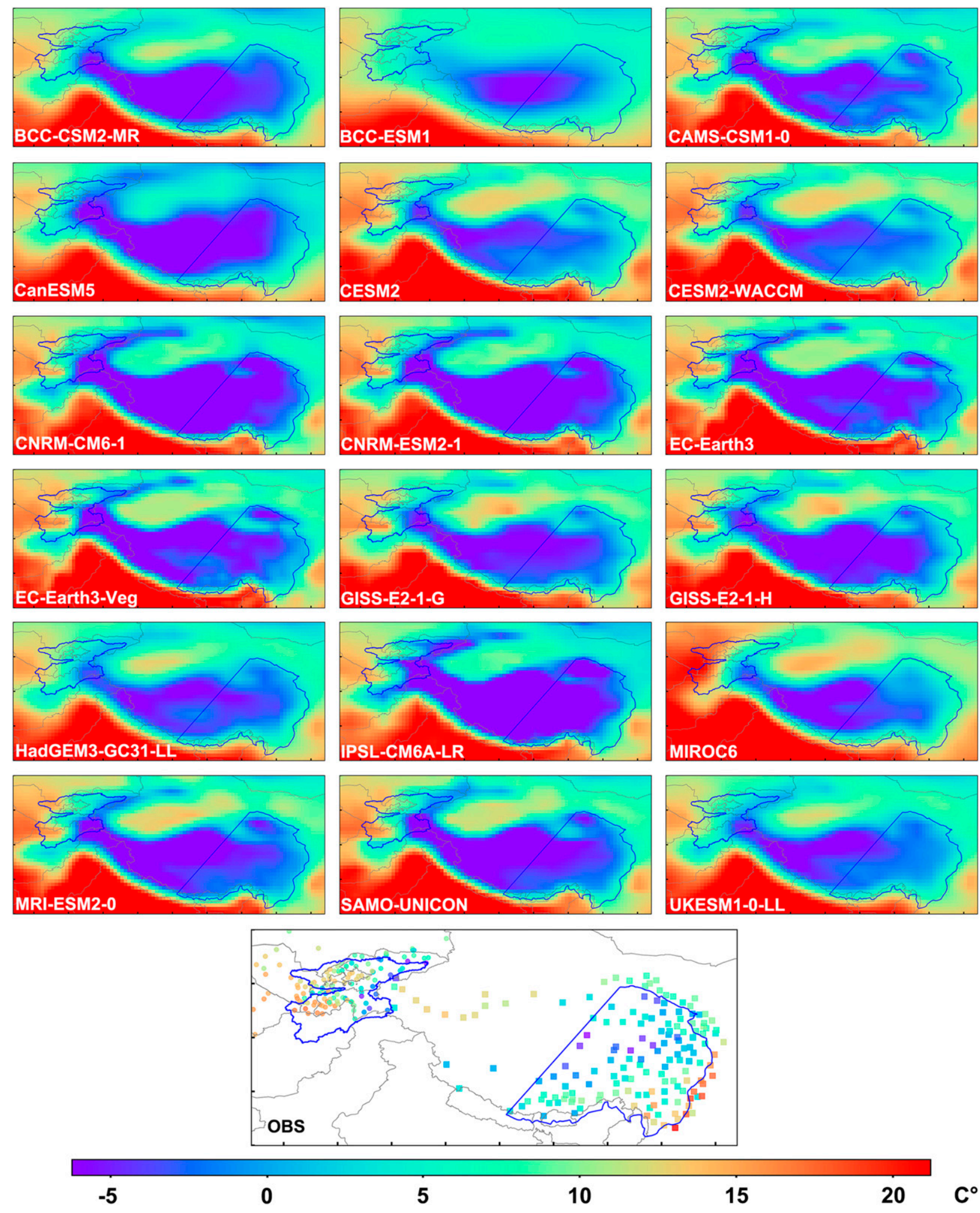

0

5

10

15

$20 \mathrm{C}^{\circ}$

FIG. 6. Spatial patterns of mean annual temperature from 18 CMIP6 models and ground-based observations (OBS) over the TP region during 1961-2014 (1961-90 for OBS in UAS). The boundaries of SETP and UAS are shown in blue. Squares and circles denote CMDC and NSIDC stations, respectively. 


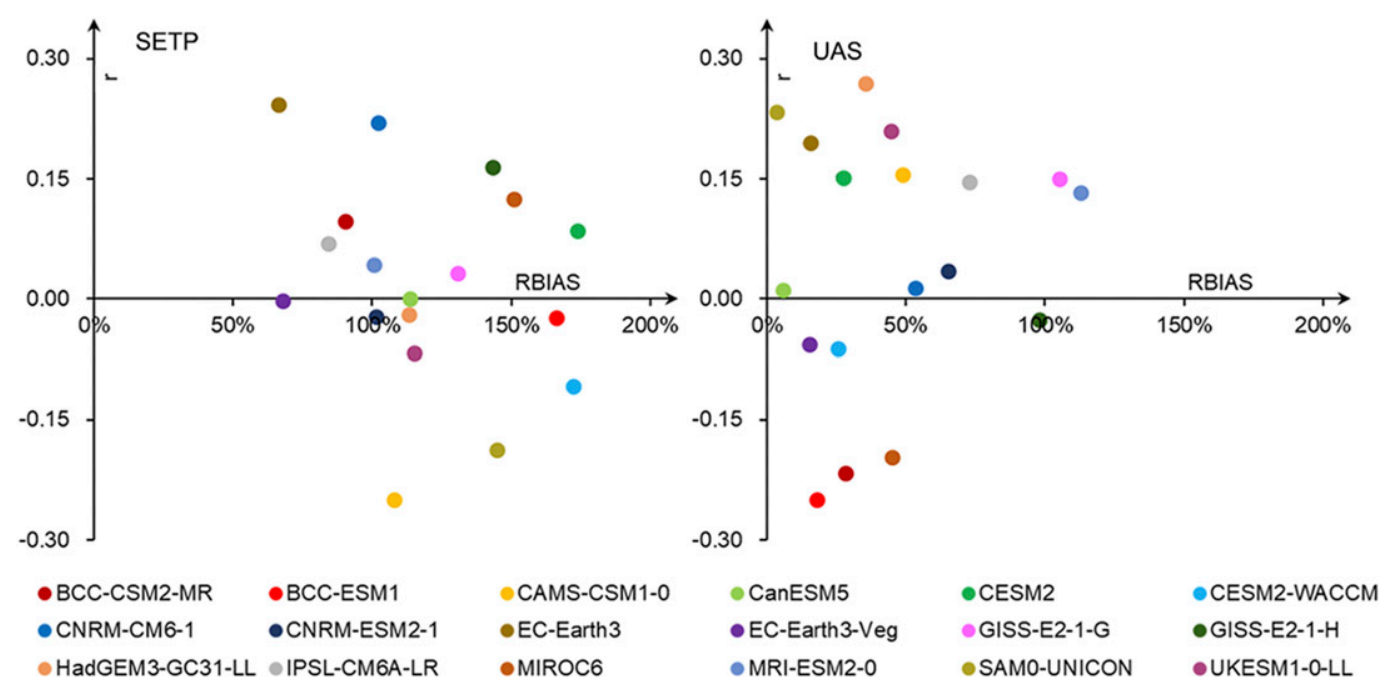

FIG. 7. RBIAS and correlation coefficient $(r)$ of historical annual precipitation predicted by 18 CMIP6 models when evaluated against observations for (left) SETP (1961-2014) and (right) UAS (1961-90). Points with black edges denote models with statistically significant $r$ values $(p<0.05)$.

the southeastern edge of SETP, a low-latitude region heavily affected by summer monsoon flows.

\section{b. Historical precipitation}

We now turn to the performance of 18 CMIP6 models in reproducing historical precipitation. The observed long-term mean annual precipitation values are $473.71 \mathrm{~mm}$ in SETP (1961-2014) and $424.29 \mathrm{~mm}$ in UAS (1961-90). Positive values of RBIAS shown in Fig. 7 suggest that all models tend to overestimate the long-term mean annual precipitation in both subregions (wet bias). Four of 18 models have RBIAS below $100 \%$ in SETP, while the vast majority of CMIP6 models (16 models) have RBIAS below $100 \%$ in UAS. In fact, the wet bias in monsoondominated SETP is more than twice as high as that in westerliesdominated UAS as measured by the RBIAS of the multimodel mean (119\% in SETP vs $46 \%$ in UAS). The wet biases of CMIP6 models over SETP and UAS are consistent with those of CMIP5 models observed previously (Su et al. 2013; Palazzi et al. 2017). For example, the values of RBIAS for all 18 CMIP6 models range widely from $66 \%$ to $174 \%$ in SETP, while Su et al. (2013) quantified RBIAS of 24 CMIP5 models over the eastern Tibetan Plateau to be $61 \%-183 \%$ (1961-2005). The persistent wet bias implies insignificant improvement of CMIP6 models from CMIP5 in the TP region. The performance of CMIP6 models in reproducing long-term mean annual precipitation is further ranked using the absolute values of RBIAS (Fig. 8). The two best performing models for long-term mean annual precipitation predictions are EC-Earth3 (RBIAS: 66\%) and EC-Earth3-Veg (68\%) in SETP, and for UAS they are SAM0-UNICON (3\%) and CanESM5 (6\%). On the other hand, the correlations between the simulated and observed annual precipitation time series are weak, as suggested by the statistically insignificant $(p<0.05) r$ values in Fig. 7. The correlation coefficients vary from -0.25 to 0.24 in SETP, and from -0.25 to 0.27 in UAS.
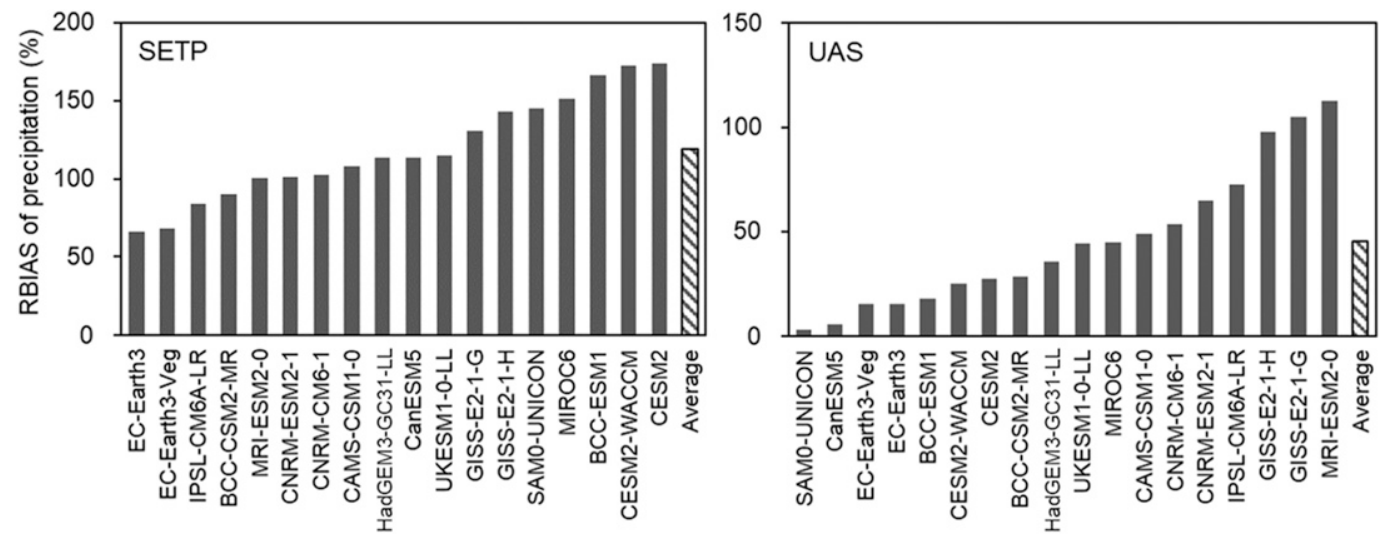

FIG. 8. The performance of 18 CMIP6 models in predicting long-term mean annual precipitation ranked based on absolute values of RBIAS for (left) SETP (1961-2014) and (right) UAS (1961-90). The hatched bar denotes RBIAS of the multimodel average 

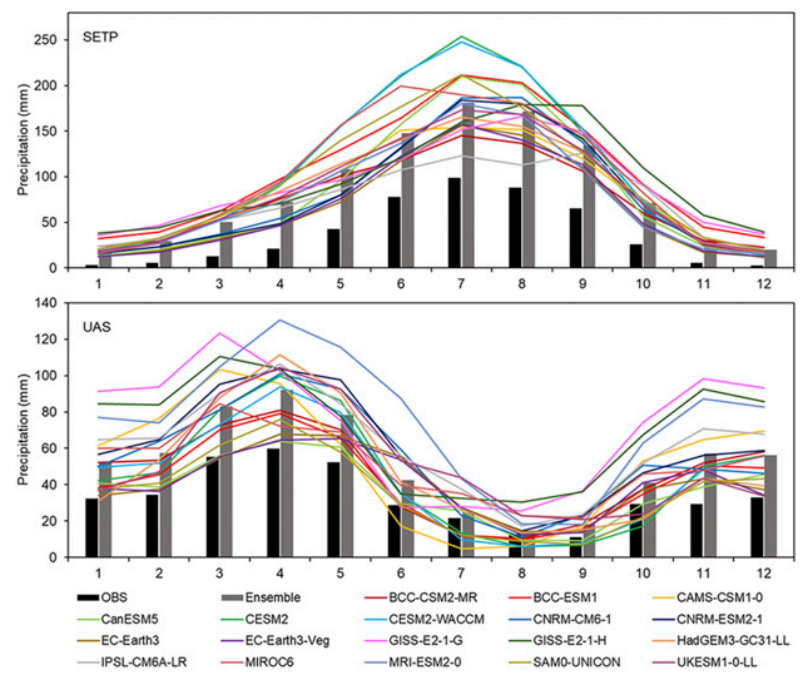

FIG. 9. Long-term mean monthly precipitation based on 18 CMIP6 models and observations in (top) SETP (1961-2014) and (bottom) UAS (1961-90). The black bar denotes observations (OBS), and the gray bar denotes the multimodel ensemble mean.

Figure 9 shows the monthly variations of historical precipitation observations and predictions from CMIP6 models. Different from its temperature counterpart, monthly precipitation exhibits a distinct intra-annual pattern in the selected two subregions, primarily induced by the contrasting atmospheric circulation patterns. In Indian-monsoon-dominated SETP, precipitation is primarily delivered by monsoon flows. On average, $48 \%$ of annual precipitation occurs in summer, as estimated by the multimodel ensemble mean, slightly lower than that based on observations (59\%), but the multimodel mean summer precipitation is $235.59 \mathrm{~mm}$ higher than observed in summer. Similar overestimation of mean monthly precipitation over SETP is also found in other seasons. Precipitation in UAS is mainly controlled by midlatitude westerlies. Most moisture is delivered as orographic precipitation in spring (spring precipitation accounts for $42 \%$ of the observed annual precipitation; cf. $41 \%$ in the simulated annual precipitation). The wet bias in spring is $85.92 \mathrm{~mm}$ for the multimodel ensemble mean. In general, monthly precipitation patterns predicted by CMIP6 models, especially the multimodel ensemble mean, are consistent with observed seasonal characteristics over both subregions, despite their distinctly different regional circulation patterns.

We then evaluate the RBIAS of the seasonal precipitation predicted by 18 models (Fig. 10). Consistent with that in mean annual precipitation, the wet bias in monsoon-dominated SETP is more pronounced than in westerlies-dominated UAS all year round. Over SETP, the largest RBIAS occurs in winter in all models, with the multimodel average over $500 \%$ (cf. $180 \%, 80 \%$, and $131 \%$ for spring, summer, and autumn, respectively). In addition to the inadequacy in modeling several physical processes in this subregion ( $\mathrm{Su}$ et al. 2013), the observed large wet biases might also be induced by the common wind-induced undercatch in snowfall measurements (Ma et al. 2015) (see section 6). All RBIAS values are positive in

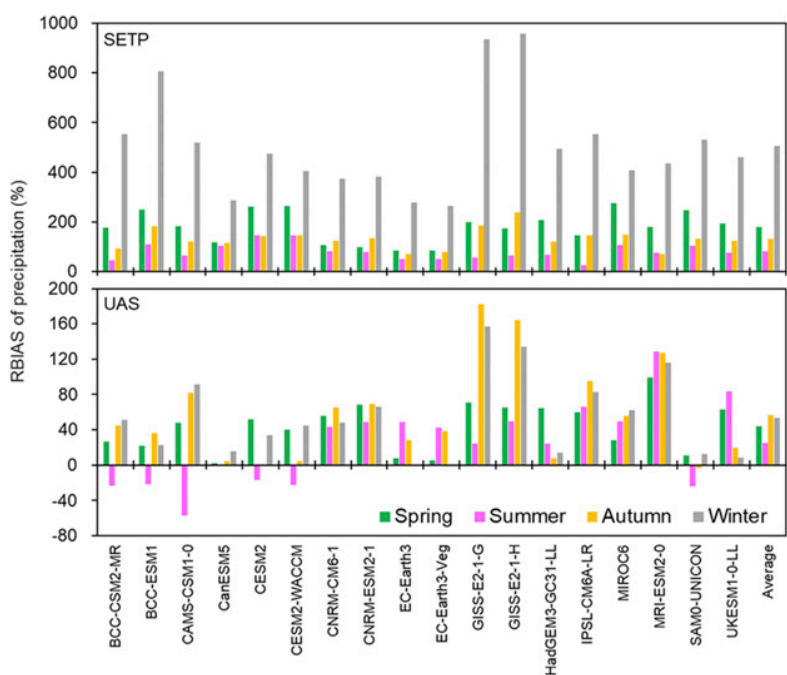

FIG. 10. RBIAS of long-term mean seasonal precipitation predicted by 18 CMIP6 models and the multimodel average when evaluated against observations for (top) SETP (1961-2014) and (bottom) UAS (1961-90).

SETP, while six models show negative RBIAS in summer in UAS. For the multimodel average in UAS, RBIAS values are $44 \%, 25 \%, 57 \%$, and $53 \%$ in spring, summer, autumn, and winter, respectively, much smaller than those in SETP. In particular, the seasonal predictions from CanESM5 are in good accordance with observations, with RBIAS values of $2.3 \%$, $-0.5 \%, 4.6 \%$, and $15.5 \%$ in four seasons. It is noteworthy that, as shown in the sensitivity analysis, the influence of different interpolation methods and spatial resolutions on the results of precipitation-related assessments is relatively minor (see the online supplemental material).

Figure 11 shows the spatial patterns of long-term mean annual precipitation predicted by CMIP6 models and observed by stations. Based on observations, mean annual precipitation over SETP gradually decreases from southeast to northwest, due largely to moisture from the southeastern slope of the Tibetan Plateau brought by the Indian monsoon (Dong et al. 2016). For UAS, midlatitude westerlies facilitate the deposition of large amounts of orographic precipitation to the windward slopes of mountainous areas, leading to relatively high annual precipitation in these areas (Curio and Scherer 2016). Despite wet biases, all CMIP6 models successfully reproduce the spatial pattern of observed mean annual precipitation over monsoon-dominated SETP, with the pixel-to-pixel correlation coefficients ranging from 0.45 (GISS-E2-1-H) to 0.83 (MRI-ESM2-0) (Table A1). However, the large precipitation amount predicted along the southwestern edge of SETP is distinct from station observations. This discrepancy reflects the potential overestimation of CMIP6 models in this transition zone with a strong elevation gradient. Only nine of 18 CMIP6 models roughly capture the observed spatial pattern of mean annual precipitation in westerlies-dominated UAS, as suggested by the statistically significant pixel-to-pixel correlations $(p<0.05$; see Table A1). Similar to that in SETP, MRIESM2-0 also shows the highest correlation coefficient $(0.54)$ in 

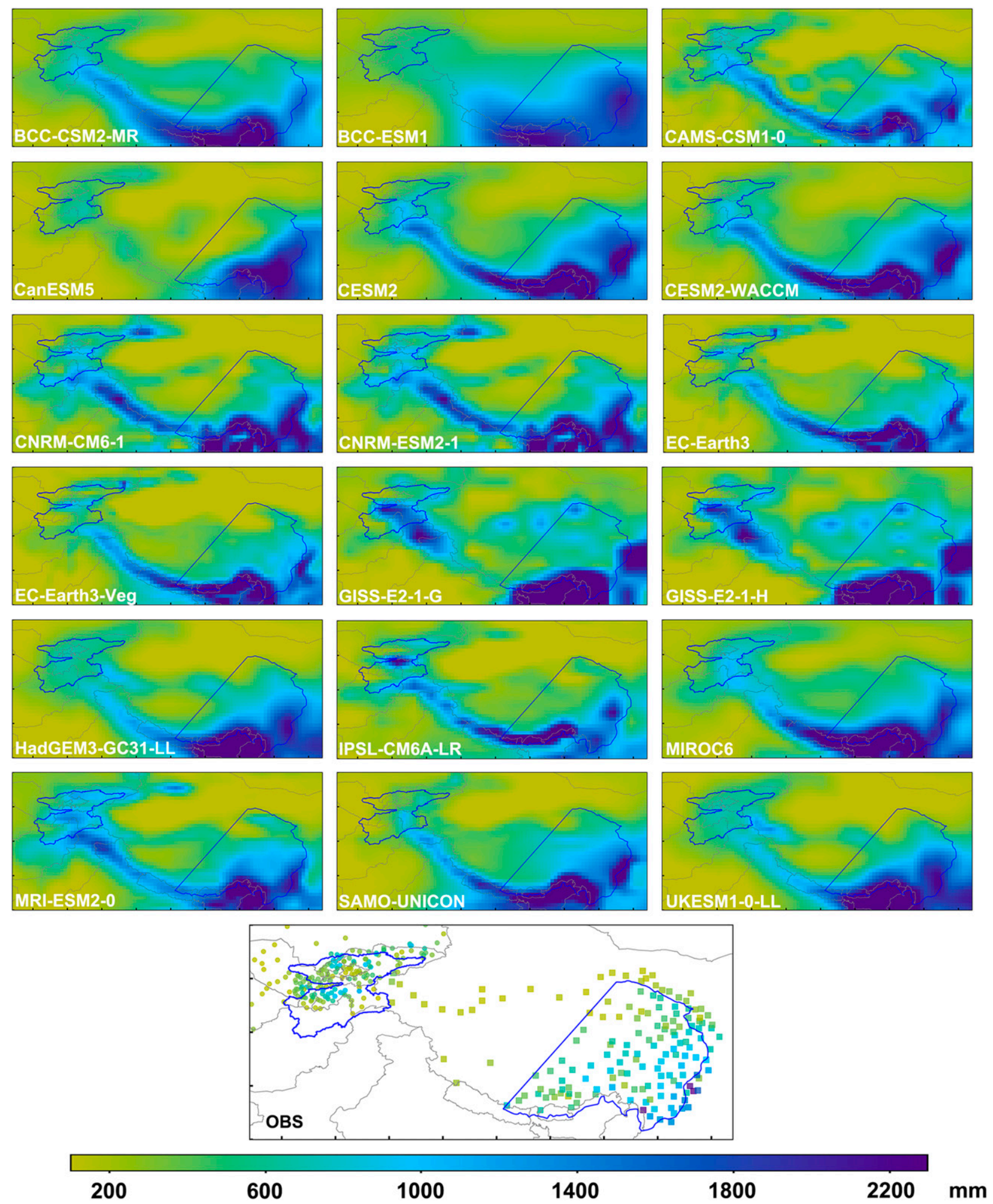

FIG. 11. Spatial patterns of mean annual precipitation from 18 CMIP6 models and ground-based observations (OBS) over the TP region during 1961-2014 (1961-90 for OBS in UAS). The boundaries of SETP and UAS are shown in blue. Squares and circles denote CMDC and NSIDC stations, respectively. 

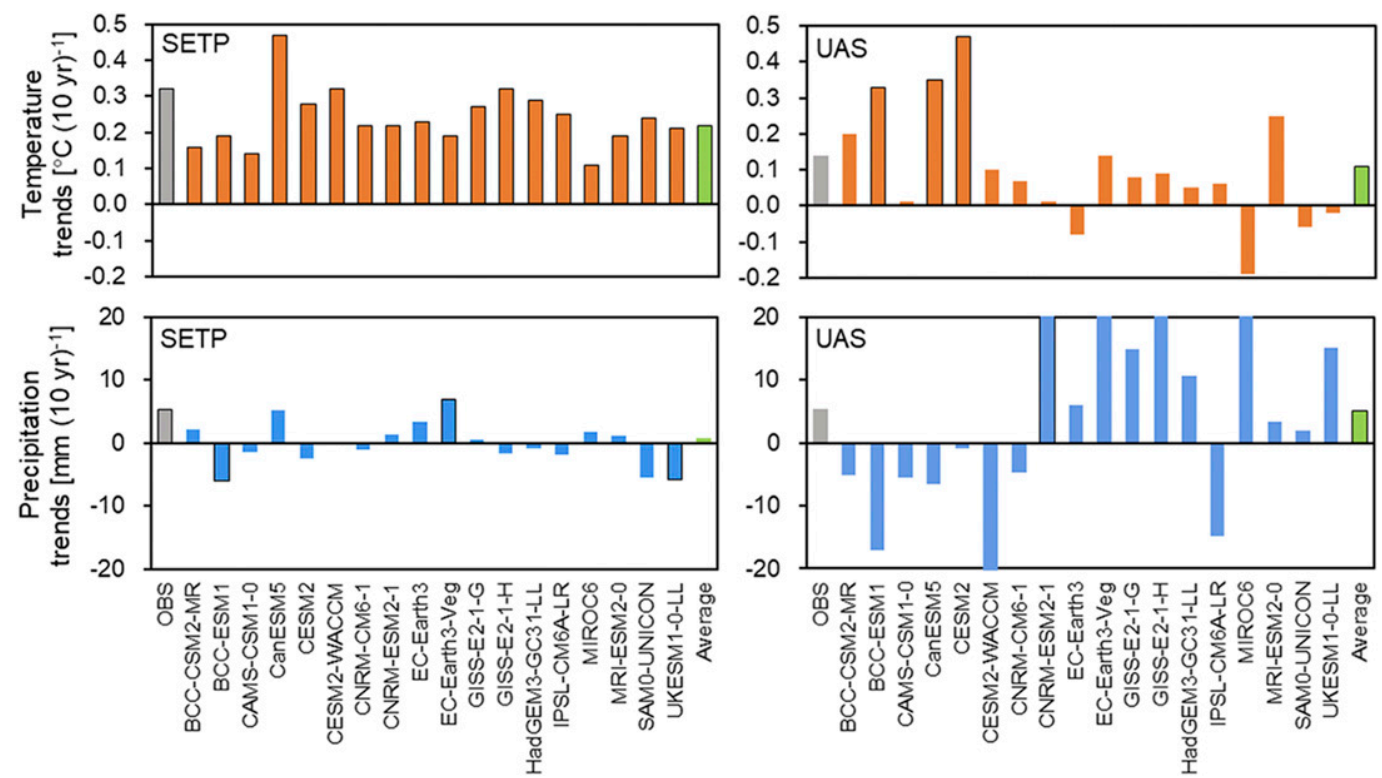

FIG. 12. Trends of historical mean annual (top) temperature and (bottom) precipitation based on CMIP6 models and observations over (left) SETP (1961-2014) and (right) UAS (1961-90). The gray bar denotes observations (OBS), and the green bar denotes the multimodel average. Bars with black edges represent statistically significant trends $(p<0.05)$. Note that for clarity, the $y$ axis is cut off at $\pm 20 \mathrm{~mm}(10 \mathrm{yr})^{-1}$ for precipitation trends in UAS (trends in CESM2-WACCM, CNRM-ESM2-1, EC-Earth3-Veg, GISS-E2-1-H, and MIROC6 are beyond this range).

UAS. In general, CMIP6 models can better reproduce spatial signals of mean annual precipitation in SETP than in UAS.

\section{c. Historical temperature and precipitation trends}

The credibility of future climate projections largely relies on how well the models can reproduce historical climate change. A thorough evaluation of the long-term historical temperature and precipitation trends is therefore necessary prior to future climate assessments (section 5). The historical trends of mean annual temperature and precipitation based on observations and CMIP6 models are shown in Fig. 12. It is clear that all CMIP6 models successfully reproduce the significant warming trend $(p<0.05)$ over monsoon-dominated SETP during 1961-2014. The warming trends are $0.32^{\circ} \mathrm{C}(10 \mathrm{yr})^{-1}$ and $0.22^{\circ} \mathrm{C}$ $(10 \mathrm{yr})^{-1}$ based on observations and multimodel average, respectively. Similarly, the predicted warming trend in westerliesdominated UAS based on the multimodel average $\left[0.11^{\circ} \mathrm{C}\right.$ $\left.(10 \mathrm{yr})^{-1}\right]$ is also in general consistent with the observations $\left[0.14^{\circ} \mathrm{C}(10 \mathrm{yr})^{-1}\right]$ for $1961-90$. Nevertheless, there is a large spread among individual models for the predicted trends of annual temperature, ranging from $-0.19^{\circ}$ to $0.47^{\circ} \mathrm{C}(10 \mathrm{yr})^{-1}$.

Although dominated by contrasting circulation systems with distinct intra-annual precipitation patterns, SETP and UAS experience similar historical wetting trends: the observed trends of annual precipitation in SETP and UAS are 5.27 and $5.35 \mathrm{~mm}(10 \mathrm{yr})^{-1}$, respectively. The ensemble means also suggest wetting trends. However, large variations in the predicted trends exist among CMIP6 models, and about half even show drying trends in both SETP and UAS. The predicted trends range from -5.97 to $6.85 \mathrm{~mm}(10 \mathrm{yr})^{-1}$ in SETP, and from -21.22 to $26.73 \mathrm{~mm}(10 \mathrm{yr})^{-1}$ in UAS. The variation of precipitation trends in UAS is much higher than that in SETP, signifying a potentially higher uncertainty of trend prediction in westerlies-dominated areas of the TP region (see section 5b). The multimodel ensemble average in general captures the historical trends of annual temperature and precipitation, and is a feasible choice to describe future climate change.

\section{Future climate projections based on CMIP6 models}

In CMIP6 experiments, the newly designed framework of future climate scenarios (SSP-RCP) synthetically describes alternative future anthropogenic drivers of climate change and socioeconomic developments, serving as the backbone of multimodel climate projections directly relevant to societal concerns about mitigation, adaptation, and impacts of climate change (O'Neill et al. 2016). It fills the critical gaps for intermediate forcing levels in CMIP5, and it standardizes all the socioeconomic and technological assumptions across models to allow more nuanced investigations among various pathways (Eyring et al. 2016; Gidden et al. 2019). In this section, we use a low scenario (SSP1-2.6), an intermediate scenario (SSP2-4.5), and a high scenario (SSP5-8.5) to investigate possible future temperature and precipitation (2015-2100) in SETP and UAS. This selection reflects a wide range of possible future climate changes with different emission pathways. The time series of multimodel average temperature and precipitation in historical (1961-2014) and future (2015-2100) periods over SETP and UAS are shown in Fig. 13. Note that prior to the time series analysis, all annual and seasonal CMIP6 predictions have been 

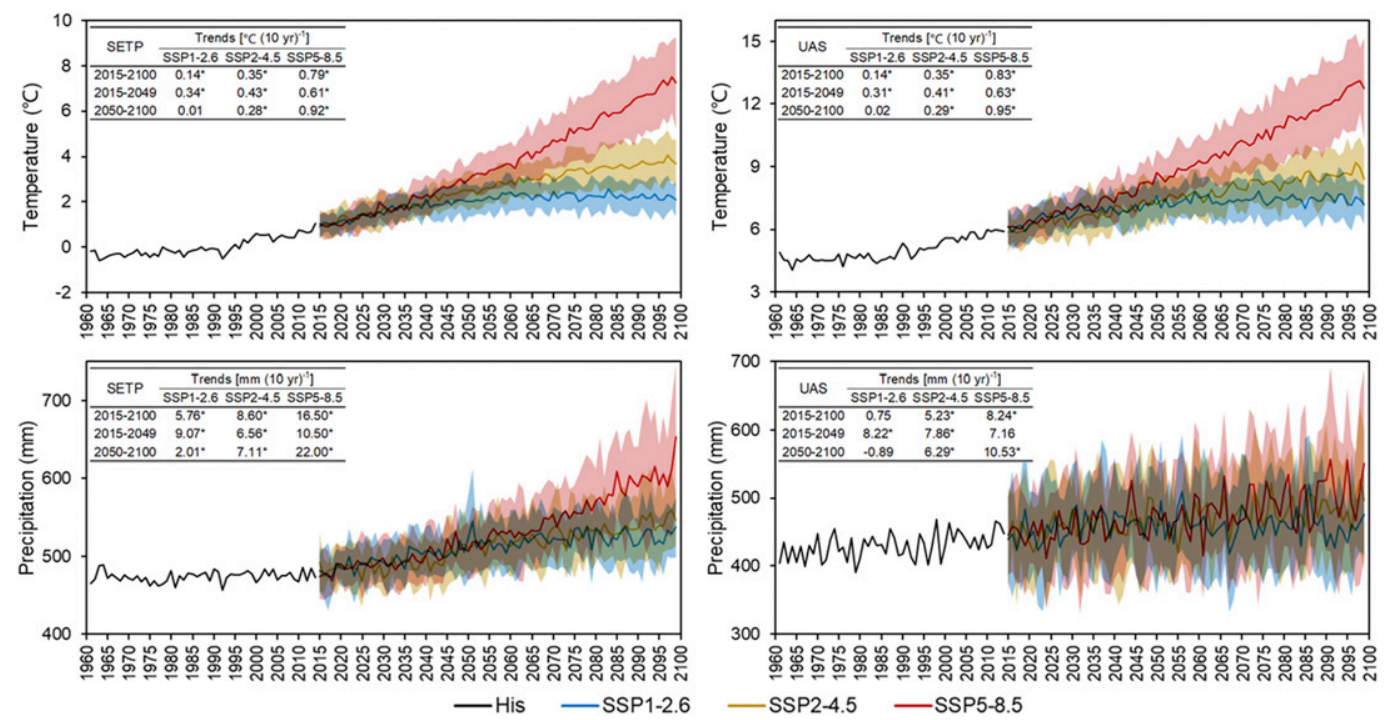

FIG. 13. Time series of multimodel ensemble mean (top) temperature and (bottom) precipitation in historical (1961-2014; His) and future (2015-2100) periods over (left) SETP and (right) UAS. Shaded areas show one standard deviation of the projections. The table in each subplot summarizes trends of different future periods, with stars representing statistically significant trends $(p<0.05)$.

bias-corrected based on corresponding historical BIAS and RBIAS (sections 3, 4a, and 4b). We further compare the trends of future annual temperature and precipitation in SETP and UAS with their global counterpart; results are shown in Fig. 14.

\section{a. Future temperature}

In the twenty-first century (2015-2100), temperature is projected to generally maintain an increasing trend in both subregions under all three scenarios (Fig. 13 and Table 2). The warming trend under SSP1-2.6 during 2015-2100 is lower than the historical trend in monsoon-dominated SETP but close to observed in westerlies-dominated UAS. However, the warming trends under SSP5-8.5 during 2015-2100 are 6 times as strong as that under SSP1-2.6 and are much higher than historical observations (see section $4 \mathrm{c}$ ). Under the intermediate SSP2-4.5 scenario, the warming trend during 2015-2100 lies somewhere in between: higher than SSP1-2.6 but lower than SSP5-8.5. In the near term (2015-49), temperature is projected to increase by $1.19^{\circ} \mathrm{C}$ in SETP and $1.09^{\circ} \mathrm{C}$ in UAS under SSP1$2.6,1.51^{\circ} \mathrm{C}$ in SETP and $1.44^{\circ} \mathrm{C}$ in UAS under SSP2-4.5, and $2.14^{\circ} \mathrm{C}$ in SETP and $2.21^{\circ} \mathrm{C}$ in UAS under SSP5-8.5. That is to
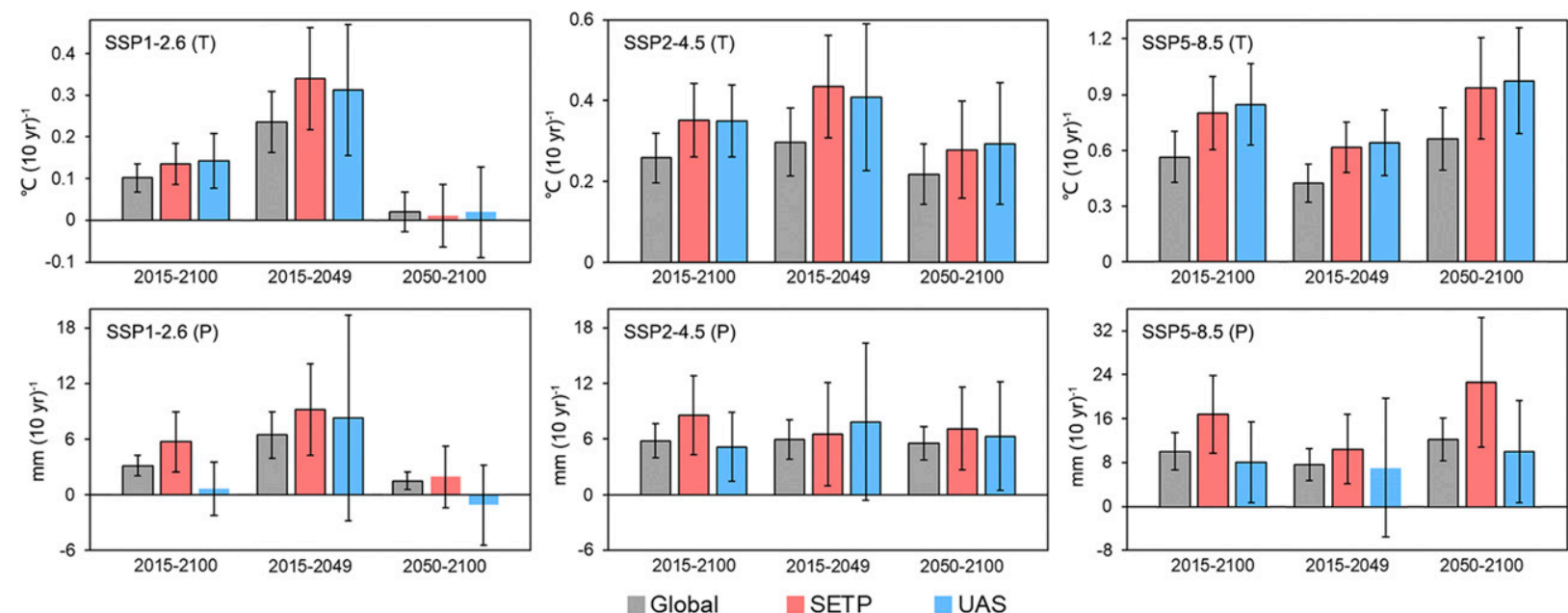

FIG. 14. Trends of future annual (top) temperature $T$ and (bottom) precipitation $P$ for the globe (Global), SETP, and UAS based on CMIP6 models during the entire future period (2015-2100), the near term (2015-49), and the far term (2050-2100) under (left) SSP1-2.6, (middle) SSP2-4.5, and (right) SSP5-8.5. Bars with black edges represent statistically significant trends $(p<0.05)$. Error bars represent one standard deviation of all trends. 
TABLE 2. Future trends of seasonal temperature $\left[{ }^{\circ} \mathrm{C}(10 \mathrm{yr})^{-1}\right.$ ] predicted by the multimodel average under SSP1-2.6, SSP2-4.5, and SSP5-8.5 scenarios in SETP and UAS. SPR, SUM, AUT, and WIN are spring, summer, autumn, and winter, respectively. Asterisks (*) indicate statistically significant trends with $p<0.05$.

\begin{tabular}{|c|c|c|c|c|c|c|c|c|c|c|c|c|c|}
\hline & & \multicolumn{4}{|c|}{ SSP1-2.6 } & \multicolumn{4}{|c|}{ SSP2-4.5 } & \multicolumn{4}{|c|}{ SSP5-8.5 } \\
\hline & & SPR & SUM & AUT & WIN & SPR & SUM & AUT & WIN & SPR & SUM & AUT & WIN \\
\hline \multirow[t]{3}{*}{ SETP } & 2015-2100 & $0.12 *$ & $0.15^{*}$ & $0.16^{*}$ & $0.16^{*}$ & $0.35^{*}$ & $0.36^{*}$ & $0.41 *$ & $0.41 *$ & $0.81 *$ & $0.78^{*}$ & $0.92 *$ & $0.92 *$ \\
\hline & 2015-49 & $0.29 *$ & $0.38^{*}$ & $0.44 *$ & $0.36^{*}$ & $0.44 *$ & $0.46^{*}$ & $0.54 *$ & $0.46^{*}$ & $0.58^{*}$ & $0.61 *$ & $0.75^{*}$ & $0.72 *$ \\
\hline & $2050-2100$ & 0.00 & 0.01 & -0.01 & 0.04 & $0.29 *$ & $0.29 *$ & $0.34 *$ & $0.30 *$ & $0.93^{*}$ & $0.90 *$ & $1.07 *$ & $1.12 *$ \\
\hline \multirow[t]{3}{*}{ UAS } & 2015-2100 & $0.14 *$ & $0.16^{*}$ & $0.15^{*}$ & $0.18 *$ & $0.35 *$ & $0.40^{*}$ & $0.38 *$ & $0.39 *$ & $0.82 *$ & $0.94 *$ & $0.93 *$ & $0.94 *$ \\
\hline & 2015-49 & $0.28 *$ & $0.36^{*}$ & $0.33^{*}$ & $0.38 *$ & $0.36^{*}$ & $0.52 *$ & $0.40 *$ & $0.50^{*}$ & $0.67 *$ & $0.66 *$ & $0.71 *$ & $0.72 *$ \\
\hline & $2050-2100$ & 0.03 & -0.01 & 0.02 & 0.05 & $0.32 *$ & $0.31^{*}$ & $0.30 *$ & $0.35^{*}$ & $0.92 *$ & $1.06^{*}$ & $1.09 *$ & $1.07 *$ \\
\hline
\end{tabular}

say, the warming trends under SSP5-8.5 are about twice those under SSP1-2.6 in both subregions during this period, in response to the rapid increase in greenhouse gas emissions and radiative forcing. However, during the far term (2050-2100), the warming trends will slow down and almost disappear under SSP1-2.6, and toward the end of this century, the marginal temperature increases in SETP and UAS will be $0.05^{\circ}$ and $0.10^{\circ} \mathrm{C}$ (above 2050 levels), respectively, in model projections. Compared to their near-term counterparts, the far-term warming trends under SSP2-4.5 will slightly decrease in both SETP and UAS. In contrast, the warming trends are projected to further accelerate under SSP5-8.5, resulting in temperature increases of $4.60^{\circ}$ and $4.75^{\circ} \mathrm{C}$ for SETP and UAS, respectively.

Future warming trends in both subregions are generally consistent with global trends. However, compared to global warming trends, the warming trends in SETP and UAS are relatively higher under all three scenarios in the near term and the entire future period (Fig. 14). During the entire future period (2015-2100) under SSP1-2.6, SSP2-4.5, and SSP5-8.5 scenarios, the warming trends in SETP and UAS are $34 \%$, $36 \%$, and $42 \%$ and $40 \%, 36 \%$, and $50 \%$ higher than the global mean, respectively. Specifically, the warming trend in UAS is consistently higher than that in SETP under SSP5-8.5 for all three future terms.

We further estimate the trends of seasonal temperature in the entire future period, the near term, and the far term. Results are summarized in Table 2. During the entire future period, the warming trends in different seasons under the same scenario are relatively consistent, and seasonal warming trends under SSP5-8.5 are consistently higher than those under SSP12.6 and SSP2-4.5 in both subregions. For the near-term projections under SSP1-2.6, the highest warming trends will occur in autumn in monsoon-dominated SETP and in winter in westerlies-dominated UAS, although warming trends will become insignificant in the far term. In contrast, despite the accelerated warming trend in the far term, both the near-term and far-term projections under SSP5-8.5 show relatively stronger warming trends in autumn and winter than in other seasons in both SETP and UAS.

\section{b. Future precipitation}

In the entire future period from 2015 to 2100 , the annual precipitation over SETP is projected to significantly increase under all three scenarios, and the wetting trends are stronger than historical observations (Figs. 12 and 13; cf. section 4c). As suggested by model projections, the rates of annual precipitation increase under SSP2-4.5 and SSP5-8.5 are 63\% and 213\% higher than the historical rate. Compared to the historical trend, the wetting trends over UAS for the same future period are milder under SSP1-2.6 and SSP2-4.5 but 54\% higher under SSP5-8.5. These projected changes suggest a relatively weak impact of future global warming on annual precipitation increase over the westerlies-dominated subregions in the TP. From the near-term to the far-term, the wetting trends under SSP1-2.6 are projected to attenuate significantly over both subregions. For example, the trend in SETP will decrease from $9.07 \mathrm{~mm}(10 \mathrm{yr})^{-1}$ in the near term to $2.01 \mathrm{~mm}(10 \mathrm{yr})^{-1}$ in the far term. Under SSP2-4.5, wetting trends will remain relatively stable in SETP and UAS. However, wetting will further accelerate in the far term under SSP5-8.5 in both subregions; the far-term increasing trend of annual precipitation will even double its near-term counterpart in SETP.

During the entire future period, the wetting trends in SETP are $81 \%, 47 \%$, and $66 \%$ higher than the global mean under SSP1-2.6, SSP2-4.5, and SSP5-8.5 scenarios, respectively (Fig. 14). For UAS, the increasing trends of annual precipitation attenuate to only $20 \%, 89 \%$, and $80 \%$ of the global mean for the entire future period under SSP1-2.6, SSP2-4.5, and SSP5-8.5, respectively. In the near term, the wetting trends are close to the global mean in both subregions. Similar to historical simulations (see section 4c), large intermodel variabilities exist in UAS under all three scenarios (e.g., projected drying trends for some models). This suggests relatively higher uncertainties of CMIP6 models in describing future (and historical) annual precipitation trends in the westerlies-dominated subregions (like UAS) when compared to monsoon-dominated TP subregions.

Table 3 summarizes the trends of seasonal precipitation projections in the entire future period, the near term, and the far term. Seasonal precipitation trends have relatively greater discrepancies when compared to seasonal temperature trends (Table 2). For precipitation projections in the monsoondominated SETP, the strongest wetting trends are in summer, while the weakest trends occur in winter under all three scenarios in all future terms. The far-term trend of SETP winter precipitation under SSP1-2.6 is even negative (although statistically insignificant), suggesting a possible drying trend toward the end of this century. In contrast, significant wetting 
TABLE 3. Future trends of seasonal precipitation $\left[\mathrm{mm}(10 \mathrm{yr})^{-1}\right]$ predicted by the multimodel average under SSP1-2.6, SSP2-4.5, and SSP5-8.5 scenarios over SETP and UAS. SPR, SUM, AUT, and WIN are spring, summer, autumn, and winter, respectively. Asterisks (*) indicate statistically significant trends with $p<0.05$.

\begin{tabular}{|c|c|c|c|c|c|c|c|c|c|c|c|c|c|}
\hline & & \multicolumn{4}{|c|}{ SSP1-2.6 } & \multicolumn{4}{|c|}{ SSP2-4.5 } & \multicolumn{4}{|c|}{ SSP5-8.5 } \\
\hline & & SPR & SUM & AUT & WIN & SPR & SUM & AUT & WIN & SPR & SUM & AUT & WIN \\
\hline \multirow[t]{3}{*}{ SETP } & $2015-2100$ & $1.09 *$ & $3.27 *$ & $1.48^{*}$ & $0.17 *$ & $1.80 *$ & $4.87 *$ & $2.07 *$ & $0.18 *$ & $3.78 *$ & $8.27 *$ & $4.13^{*}$ & $0.36^{*}$ \\
\hline & 2015-49 & $1.98 *$ & $5.22 *$ & $1.75^{*}$ & $0.29 *$ & $1.31 *$ & $3.44 *$ & $1.41 *$ & $0.29 *$ & $2.58^{*}$ & $5.53^{*}$ & $2.56^{*}$ & $0.21 *$ \\
\hline & $2050-2100$ & $0.73^{*}$ & 0.83 & 0.69 & -0.04 & $1.48^{*}$ & $4.45^{*}$ & $1.45^{*}$ & 0.13 & $5.11 *$ & $11.08^{*}$ & $5.66^{*}$ & $0.40^{*}$ \\
\hline \multirow[t]{3}{*}{ UAS } & $2015-2100$ & 0.36 & 0.40 & -0.56 & 0.74 & $2.24 *$ & -0.38 & $1.07 *$ & $2.33 *$ & $3.45^{*}$ & $-2.01 *$ & 0.76 & $5.78^{*}$ \\
\hline & 2015-49 & 2.15 & 0.81 & 2.07 & $3.83^{*}$ & 1.20 & -0.90 & $4.32 *$ & 2.28 & 0.29 & 0.72 & $2.67 *$ & $4.39 *$ \\
\hline & $2050-2100$ & -2.33 & 0.84 & -0.15 & 0.65 & 2.43 & 0.34 & 1.16 & $2.78^{*}$ & 2.99 & $-1.65^{*}$ & 1.11 & $7.57 *$ \\
\hline
\end{tabular}

trends in westerlies-dominated UAS mainly occur in cold seasons under all future scenarios. It is noteworthy that summers in UAS are projected to experience significant drying $(p<0.05)$ under SSP5-8.5 in the far term and the entire future period, despite the overall increasing annual precipitation. Similar summer drying is also projected under SSP2-4.5 in the near term and the entire future period, although statistically insignificant. The potential summer drying indicates intensified uneven distributions of seasonal precipitation in this subregion. On the other hand, the near-term significant wetting trend in winter over UAS will become marginal during 2050-2100 under SSP1-2.6, whereas the winter wetting trend will further intensify in the far term under SSP2-4.5 and SSP5-8.5 scenarios. These seasonal differences in model projections imply that the TP region will likely experience a significant wetting trend in summer in the Indian-monsoon-dominated parts (e.g., SETP) but in winter in the westerlies-dominated parts (e.g., UAS).

\section{Discussion}

Assessments in section 4 suggest large biases in historical temperature and precipitation predicted by most CMIP6 models. The presence of cold and wet biases is in general consistent with that observed in previous CMIP5 studies over the Tibetan Plateau (Su et al. 2013; Chen and Frauenfeld 2014; Chen et al. 2017; Zhu and Yang 2020). In fact, this region has been identified to have the largest biases in CMIP outputs in China (Chen and Frauenfeld 2014; Xin et al. 2020; Zhu et al. 2020; You et al. 2021). To further evaluate whether there is any significant improvement in the performance of CMIP6 models from that of CMIP5 models over the selected two subregions, here we compare the spatial patterns simulated by a set of five CMIP6 models (BCC-CSM2-MR, CanESM5, CNRM-CM6-1, GISS-E2-1-H, HanGEM3-GC31-LL, and IPSL-CM5S-LR) and their CMIP5 predecessors (BCC-CSM1.1, CanESM2, CNRM-CM5, GISS-E2-H, HanGEM2-AO, and IPSL-CM5SLR) available at the time of our investigation. Each selected pair of models share an identical or similar dynamic core. Results of simulated historical mean annual temperature and precipitation (1961-2005) are shown in Fig. 15, and the BIAS, RBIAS, and $r$ values when evaluated against historical observations are summarized in Fig. 16.

As suggested by Fig. 15, the spatial patterns and magnitudes of both mean annual temperature and precipitation simulated by the selected five CMIP6 models are nearly identical to those of their CMIP5 predecessors. Quantitative assessments in Fig. 16 reveal a wide spread of BIAS, RBIAS, and $r$ values for both subregions in both CMIP5 and CMIP6 models. The performance of some CMIP6 models in reproducing the interannual temperature and precipitation variations has been improved from their CMIP5 counterparts but with increased BIAS and/or RBIAS. For example, compared to IPSLCM5A-LR, IPSL-CM6A-LR has a greater $r$ value for the simulated annual precipitation time series in UAS; meanwhile, its RBIAS for mean annual precipitation increases from $43 \%$ to $73 \%$ (Fig. 16). Similar tradeoffs are also observed in monthly temperature and precipitation simulations (see Fig. S5 in the online supplemental material). These comparisons confirm our qualitative comparisons with previous CMIP5 studies (as detailed in section 4) that the improvement of CMIP6 models for temperature and precipitation simulations (especially the mean fields) in these two subregions is relatively limited. Note that the conclusions here can be affected by many factors, including the number of models, evaluation periods, and the number of stations, and therefore involve uncertainties. Although beyond the scope of this study, a more thorough and systematic comparison with all available CMIP6 successors should be conducted to deepen our understanding of model improvements in this critical region.

We then turn to the biases of historical climate simulations and their potential causes. Figure 17 shows the relationships between long-term mean annual temperature BIAS and precipitation RBIAS, as well as their dependence on numerical spatial resolution in both subregions. For SETP, there is a strong linear relationship between temperature BIAS and precipitation RBIAS $\left(11.74 \%{ }^{\circ} \mathrm{C}^{-1}, p<0.05\right)$, suggesting that the reduction of cold bias is nearly linearly associated with the amplified wet bias in the Indian-monsoon-dominated areas over the TP. This trade-off between cold bias and wet bias signifies the great challenge to simultaneously improve precipitation and temperature predictions in SETP. In contrast, there is no clear relationship between cold bias and wet bias in westerlies-dominated UAS. On the other hand, previous studies have suggested that a higher spatial resolution of GCMs might significantly improve the accuracy of historical simulations, especially in regions with complex topographic features such as the TP region (Koutroulis et al. 2016; Jain et al. 2019; Rahimi et al. 2019). Similar improvements due to the 
Mean of 5 models in CMIP5

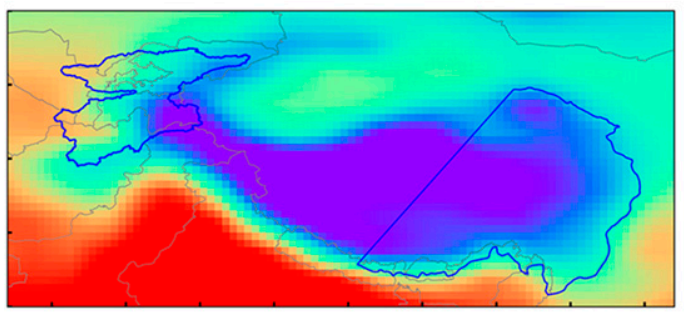

0

5

10

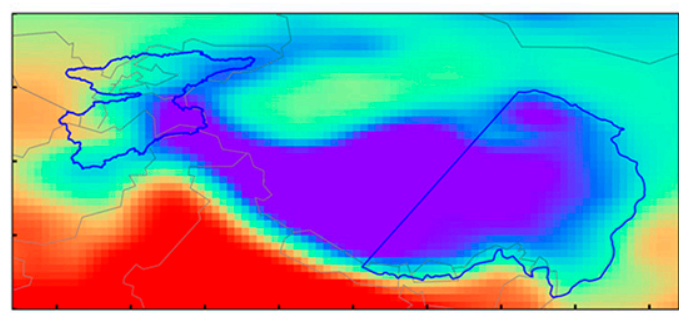

15

20
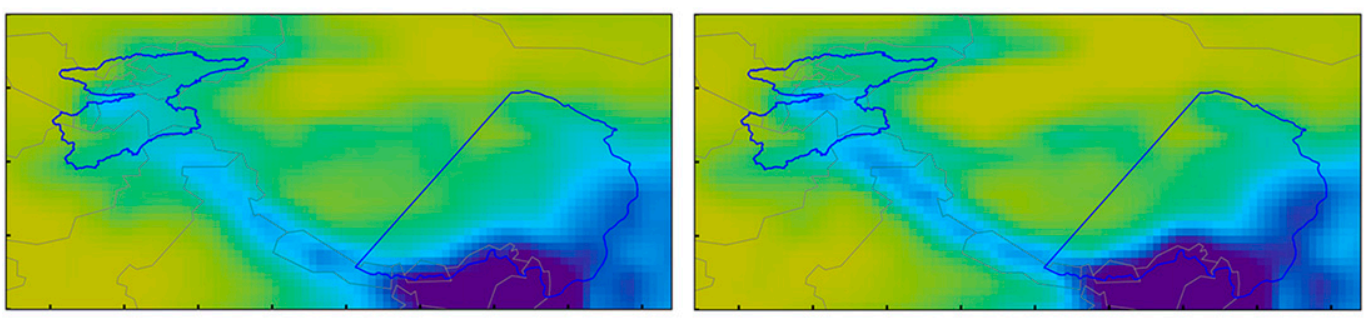

600

1000

1400

1800

$2200 \mathrm{~mm}$

FIG. 15. Spatial patterns of mean annual (top) temperature and (bottom) precipitation simulated by (right) a set of five CMIP6 models and (left) their CMIP5 predecessors over the TP region for 1961-2005. The boundaries of SETP and UAS are shown in blue.

increase in spatial resolution are observed for temperature BIAS over both subregions. For example, models with lower temperature BIAS in UAS in general have higher spatial resolutions. This highlights the importance of fine spatial resolution in improving temperature predictions over the TP region.

However, as shown in Fig. 17, higher resolution does not necessarily improve the accuracy of precipitation predictions, likely because the spatial resolutions of the analyzed CMIP6 models are still too low and unable to significantly reduce the wet bias in both representative subregions. This is also supported by a recent study based on the Weather Research and Forecasting model (Lin et al. 2018), which showed that increasing the spatial resolution from $30 \mathrm{~km}$ (finer than the finest CMIP6 models analyzed here) to $2 \mathrm{~km}$ would significantly reduce the wet bias during a summer monsoon season in the Tibetan Plateau. In particular, fine model resolutions improve subgrid orographic drag with heterogeneous surface forcing and alleviate the excessive amount of water vapor transported from the Himalayas, which can more realistically reproduce precipitation over the Tibetan Plateau (Gao et al. 2015; Lin et al. 2018; Li et al. 2021).

The cold bias seems to be a persistent feature in both CMIP5 and CMIP6 over the TP region, especially in SETP during cold seasons (spring and winter) and the southeastern part of SETP (Figs. 4-6). In general, the entire TP region is dominated by midlatitude westerlies in cold seasons, with the surface wind split into northern and southern branches as induced by its high elevation. The southern branch forms a strong warm advection by passing through the northern Indian subcontinent, leading to higher temperatures over the southeastern edge of the Tibetan Plateau where elevation is relatively low (Jiao et al. 2016). The cold bias over this region likely implies that, besides the spatial resolution issue, physical processes related to this warm advection are not sufficiently captured in most models. More specially, Chen et al. (2017) examined a suite of physically interlinked processes contributing to the cold bias over the Tibetan Plateau, and found that smaller surface turbulent fluxes in CMIP5 models can lead to a colder lower-tropospheric temperature and a lower water vapor content, which in turn can cause negative clear-sky downward longwave radiation as well as the cold bias.

The wet bias may result from multiple factors including both numerical models and observational data. On the one hand, the overestimated precipitation in UAS is likely because the orographic precipitation induced by the uplift of the westerly flow is insufficiently resolved in models (Maussion et al. 2014; Curio and Scherer 2016; Lin et al. 2018). This is also suggested by the severely overestimated SETP precipitation in winter, in which the subregion is governed by the westerlies instead of the Indian monsoon system. On the other hand, the wind-induced undercatch of snowfall measurements, a common phenomenon in the cold and windy TP region (Ma et al. 2015), can also lead to the systematic cold bias. For example, the correction factor of the undercatch of winter precipitation can be even greater than $200 \%$ in the central and northeastern Tibetan Plateau, by a bias-adjustment model based on wind speed and temperature (Yang et al. 2001; Ma et al. 2015). Additionally, the spatial interpolation method used here is unable to fully capture the influence of complex terrain in the TP region. Precipitation has been found to decrease with increasing evaluation from 2 to $6 \mathrm{~km}$ over the TP region (Tang et al. 2018), while interpolating based on rain gauges with relatively flat topography will not fully reflect such a strong spatial variability. Furthermore, although 

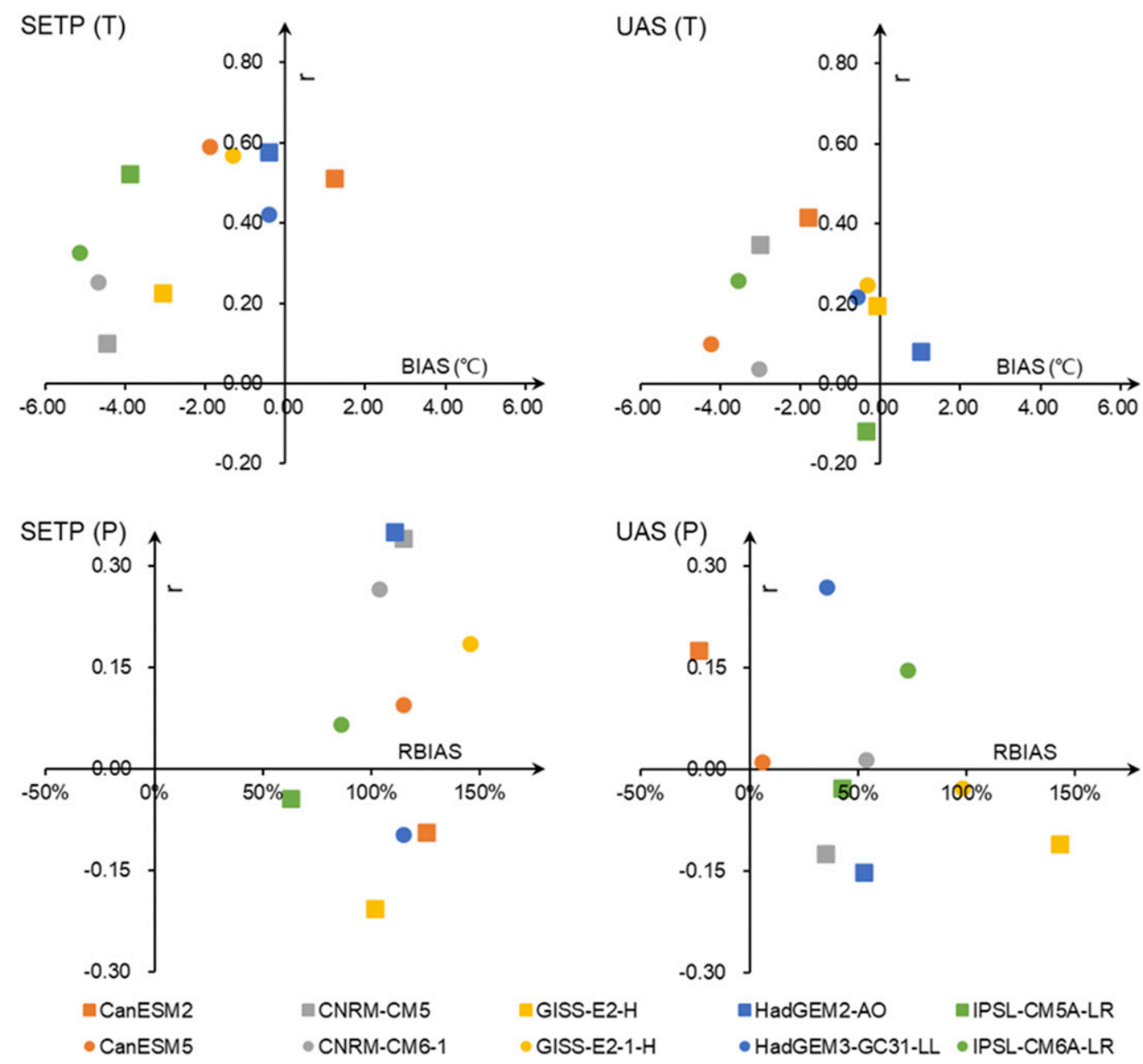

FIG. 16. BIAS (RBIAS) and correlation coefficient $r$ of historical annual temperature $T$ (precipitation $P$ ) predicted by five CMIP6 models (denoted by circles) and their CMIP5 predecessors (denoted by squares) when evaluated against observations for (left) SETP (1961-2005) and (right) UAS (1961-90).

the sensitivity analysis suggests that temperature and precipitationrelated assessments are in general insensitive to different spatial interpolation methods (see the online supplemental material), the selected interpolation methods are still very simple and may not capture the influence of orographic lift on precipitation. For example, Adam et al. (2006) suggested that the correction of orographic effects can result in a net global terrestrial precipitation (1979-99 climatology) increase of about 6\% and an increase of over $20 \%$ over orographically influenced regions.

It is noteworthy that for the historical simulations of CMIP6 models in this study, we evaluated the results of temperature and precipitation using available station observations. However, the estimated annual averages, BIAS, RBIAS, and $r$ values can be influenced not only by spatial resolutions and interpolation methods (see the online supplemental material) but also by the number of stations and evaluation periods (e.g., Chen and Frauenfeld 2014). In addition, the evaluations are based on only three commonly used metrics (BIAS, RBIAS, and $r$ ) to facilitate comparisons with existing studies. However, these three metrics cannot fully describe the statistical relationships between model simulations and observations (e.g., potential nonlinear relationships). Moreover, the evaluations herein are limited to temperature and precipitation, while other model diagnostics, especially those closely related to regional circulations (e.g., Indian summer monsoon index) (Jie et al. 2017), are not considered. Future evaluations for these two subregions should take into account other related model diagnostics and fully assess the skill of CMIP6 in reproducing key physical processes with additional metrics, such as skill scores and network metrics (Koutroulis et al. 2016; Wang and Wang 2020). Nevertheless, this study lays a foundation for several subsequent studies (including a more thorough evaluation of CMIP5 vs CMIP6) and provides new insights into the performance of CMIP6 models and their applications in the TP region, such as the selection of GCMs for regional hydrological modeling.

\section{Conclusions}

In this study, we evaluated the performance of 18 CMIP6 models in reproducing historical surface air temperature and precipitation based on observations over the TP region, with a 

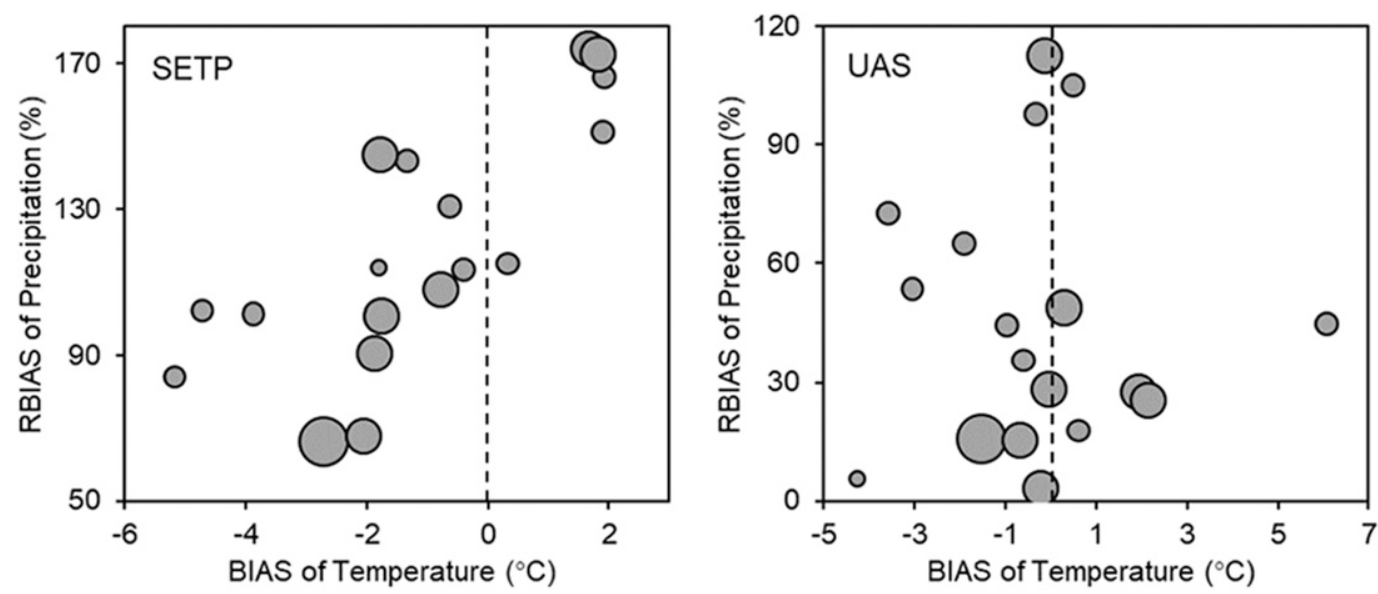

FIG. 17. Relationships between BIAS of long-term mean annual temperature and RBIAS of long-term mean annual precipitation in historical simulations of 18 CMIP6 models over (left) SETP and (right) UAS. Circle size represents the model spatial resolution (the smallest circle: $500 \mathrm{~km}$; the largest circle: $50 \mathrm{~km}$ ). The dashed line denotes zero temperature BIAS.

focus on Indian-monsoon-dominated SETP (1961-2014) and westerlies-dominated UAS (1961-90) subregions equipped with densely distributed stations. We also analyzed future climate in the entire future period (2015-2100), the near term (2015-49), and the far term (2050-2100) in these two representative subregions using bias-corrected projections under SSP1-2.6, SSP2-4.5, and SSP5-8.5 scenarios. The main conclusions are the following:

1) CMIP6 models are able to reproduce the intra-annual variability and spatial pattern of observed temperature and precipitation over the TP region. However, cold and wet biases detected in CMIP5 models still exist in this region, which might be attributable to low spatial resolution and inadequate representation of physical processes in models as well as measurement errors. The cold and wet biases over monsoon-dominated SETP are greater than those over westerlies-dominated UAS. The multimodel average cold biases in SETP and UAS are $1.18^{\circ}$ and $0.32^{\circ} \mathrm{C}$, respectively, while the wet biases in SETP and UAS are $119 \%$ and $46 \%$, respectively. No single model outperforms all other models in both temperature and precipitation in the TP region.

2) Cold biases mainly occur in spring and winter over the TP region. The multimodel mean BIAS values in four seasons are $-1.94^{\circ} \mathrm{C}$ (spring), $-0.12^{\circ} \mathrm{C}$ (summer), $-0.61^{\circ} \mathrm{C}$ (autumn), and $-2.05^{\circ} \mathrm{C}$ (winter) over SETP, and are $-1.19^{\circ}$, $0.62^{\circ}, 0.04^{\circ}$, and $-0.76^{\circ} \mathrm{C}$ in UAS. Spatially, cold biases mainly exist in the southeastern edge of the TP region. Wet biases are found in all seasons over the TP region, with the strongest bias occurring in winter over monsoon-dominated SETP (506\%). The multimodel mean RBIAS values in four seasons are $180 \%, 80 \%, 131 \%$, and $506 \%$ over SETP, and are $44 \%, 25 \%, 57 \%$, and $53 \%$ in UAS. Spatially, wet biases are mainly distributed on the south slope of the TP region.

3) CMIP6 models are more capable of reproducing the historical warming trend over monsoon-dominated SETP than over westerlies-dominated UAS. Based on the multimodel ensemble mean in the entire future period, temperature is projected to keep increasing over both SETP and UAS, and the warming trends under SSP5-8.5 are about 6 times that under SSP1-2.6. SSP2-4.5 has warming trends higher than SSP1-2.6 but lower than SSP5-8.5. Compared to the global trend, warming trends are projected to be $34 \%-42 \%$ higher in SETP, and 36\%-50\% higher in UAS. From the near term to the far term, these warming trends are projected to slow down and become invisible under SSP1-2.6 in both subregions, but to further accelerate under SSP5-8.5. Future seasonal warming trends in model projections are in general consistent with their annual counterparts under both scenarios in both subregions.

4) Future wetting trends are more significant over monsoondominated SETP than westerlies-dominated UAS, as suggested by model projections. From the near term to the far term, wetting trends are projected to largely attenuate under SSP1-2.6, but to remain relatively stable under SSP24.5 and to accelerate under SSP5-8.5 in both subregions. Compared to global trends, the wetting trends are $47 \%-$ $81 \%$ higher in SETP, but in UAS they significantly attenuate to $20 \%, 89 \%$, and $80 \%$ of the global trend under SSP12.6, SSP2-4.5, and SSP5-8.5, respectively. Seasonally, the strongest and weakest wetting trends are projected to occur in summer and winter, respectively, over SETP under all three future scenarios, whereas for UAS the wetting trends mainly occur in cold seasons (especially under SSP5-8.5). Overall, model projections suggest that the TP region will experience a summer wetting trend over monsoon-dominated SETP and a winter wetting trend over westerlies-dominated UAS in the future. In addition, the intermodel variability in predicting precipitation trends is much stronger in westerliesdominated UAS than in SETP.

The biases and uncertainties observed in this study highlight the need for high-resolution climate models and improved numerical representations of atmospheric circulation systems and land-atmosphere interactions over the heterogeneous TP 
TABLE A1. Pixel-to-pixel correlations for spatial patterns of long-term historical mean annual temperature and precipitation based on CMIP6 models and observations in SETP (1961-2014) and UAS (1961-90). Asterisks (*) indicate statistically significant with $p<0.05$.

\begin{tabular}{|c|c|c|c|c|}
\hline \multirow[b]{2}{*}{ Model name } & \multicolumn{2}{|c|}{ Temperature } & \multicolumn{2}{|c|}{ Precipitation } \\
\hline & SETP & UAS & SETP & UAS \\
\hline BCC-CSM2-MR & $0.60 *$ & $0.78^{*}$ & $0.68 *$ & 0.04 \\
\hline BCC-ESM1 & $0.65^{*}$ & $0.79 *$ & $0.77 *$ & 0.01 \\
\hline CAMS-CSM1-0 & $0.71 *$ & $0.83^{*}$ & $0.74 *$ & $0.22 *$ \\
\hline CanESM5 & $0.66^{*}$ & $0.74 *$ & $0.78 *$ & $0.21 *$ \\
\hline CESM2 & $0.79 *$ & $0.87 *$ & $0.72 *$ & 0.13 \\
\hline CESM2-WACCM & $0.79 *$ & $0.87 *$ & $0.71 *$ & $0.17 *$ \\
\hline CNRM-CM6-1 & $0.74 *$ & $0.84 *$ & $0.76^{*}$ & -0.06 \\
\hline CNRM-ESM2-1 & $0.74 *$ & $0.84 *$ & $0.73^{*}$ & -0.04 \\
\hline EC-Earth3 & $0.79 *$ & $0.89 *$ & $0.71 *$ & 0.09 \\
\hline EC-Earth3-Veg & $0.79 *$ & $0.89 *$ & $0.71 *$ & 0.09 \\
\hline GISS-E2-1-G & $0.67 *$ & $0.84 *$ & $0.48 *$ & $0.20 *$ \\
\hline GISS-E2-1-H & $0.64 *$ & $0.83 *$ & $0.45^{*}$ & $0.22 *$ \\
\hline HadGEM3-GC31-LL & $0.70 *$ & $0.79 *$ & $0.79 *$ & $0.19 *$ \\
\hline IPSL-CM6A-LR & $0.78^{*}$ & $0.92 *$ & $0.49 *$ & $0.27 *$ \\
\hline MIROC6 & $0.55^{*}$ & $0.77 *$ & $0.63 *$ & 0.10 \\
\hline MRI-ESM2-0 & $0.76^{*}$ & $0.87 *$ & $0.83 *$ & $0.54 *$ \\
\hline SAM0-UNICON & $0.79 *$ & $0.88 *$ & $0.63 *$ & $0.22 *$ \\
\hline UKESM1-0-LL & $0.69 *$ & $0.78 *$ & $0.80 *$ & 0.14 \\
\hline
\end{tabular}

region. On the other hand, the projected wetting trends in a warming future (especially in 2015-49) in both subregions are highly informative to regional planning of water resources and climate risk management. For monsoon-dominated SETP, the projected precipitation increase may partly offset warminginduced glacier retreat (Bolch et al. 2012), but warming and wetting summers will increase the risks of mountain hazards (e.g., ice avalanches, debris flows, and landslides) and floods (Cui and Jia 2015), threatening the safety of downstream dams and settlements. For westerlies-dominated UAS, the projected precipitation increase in spring and winter will contribute to possible mass gain of glaciers and provide extra water to downstream irrigated agriculture in central Asia and the drying Aral Sea (White et al. 2014; Micklin 2016; Karthe et al. 2017). However, the projected intensified uneven distributions of seasonal precipitation in the future might increase the frequency of summer droughts and winter floods (Sorg et al. 2014). Proactive adaptation measures will therefore be needed in the near future to enhance water security and increase the resilience of agriculture in the downstream regions of UAS.

Acknowledgments. This work was financially supported by the Second Tibetan Plateau Scientific Expedition and Research Program (2019QZKK0201, 2019QZKK020705) and the National Natural Science Foundation of China (41988101, 41871057). The authors thank He Sun and Jingheng Huang (from the Institute of Tibetan Plateau Research, University of Chinese Academy of Sciences) for their comments and suggestions.

Data availability statement. Station data are available at http://data.cma.cn/ and https://nsidc.org/data/g02174. CMIP6 data are available at https://esgf-node.llnl.gov/projects/cmip6.

\section{APPENDIX}

\section{Pixel-to-Pixel Correlations for Temperature and Precipitation Spatial Patterns}

In this appendix, we summarize the results of pixel-to-pixel correlations for spatial patterns of long-term historical mean annual temperature and precipitation based on CMIP6 models and observations in the selected two subregions in Table A1.

\section{REFERENCES}

Adam, J. C., E. A. Clark, D. P. Lettenmaier, and E. F. Wood, 2006: Correction of global precipitation products for orographic effects. J. Climate, 19, 15-38, https://oi.org/10.1175/JCLI3604.1.

Bolch, T., and Coauthors, 2012: The state and fate of Himalayan glaciers. Science, 336, 310-314, https://doi.org/10.1126/science. 1215828.

Chen, D., and Coauthors, 2015: Assessment of past, present and future environmental changes on the Tibetan Plateau. Chinese Sci. Bull., 60, 3025-3035, https://doi.org/10.1360/N972014-01370.

Chen, L., and O. W. Frauenfeld, 2014: A comprehensive evaluation of precipitation simulations over China based on CMIP5 multimodel ensemble projections. J. Geophys. Res. Atmos., 119, 5767-5786, https://doi.org/10.1002/2013JD021190.

Chen, X., Y. Liu, and G. Wu, 2017: Understanding the surface temperature cold bias in CMIP5 AGCMs over the Tibetan Plateau. Adv. Atmos. Sci., 34, 1447-1460, https://doi.org/ 10.1007/s00376-017-6326-9.

Cui, P., and Y. Jia, 2015: Mountain hazards in the Tibetan Plateau: Research status and prospects. Natl. Sci. Rev., 2, 397-399, https://doi.org/10.1093/nsr/nwv061.

Cuo, L., Y. Zhang, F. Zhu, and L. Liang, 2014: Characteristics and changes of streamflow on the Tibetan Plateau: A review. J. Hydrol., 2, 49-68, https://doi.org/10.1016/j.ejrh.2014.08.004.

Curio, J., and D. Scherer, 2016: Seasonality and spatial variability of dynamic precipitation controls on the Tibetan Plateau. Earth Syst. Dyn., 7, 767-782, https://doi.org/10.5194/esd-7-767-2016.

Dimri, A., D. Niyogi, A. Barros, J. Ridley, U. Mohanty, T. Yasunari, and D. Sikka, 2015: Western disturbances: A review. Rev. Geophys., 53, 225-246, https://doi.org/10.1002/2014RG000460.

Dong, W., and Coauthors, 2016: Summer rainfall over the southwestern Tibetan Plateau controlled by deep convection over the Indian subcontinent. Nat. Commun., 7, 10925 , https:// doi.org/10.1038/ncomms10925.

Eyring, V., S. Bony, G. A. Meehl, C. A. Senior, B. Stevens, R. J. Stouffer, and K. E. Taylor, 2016: Overview of the Coupled Model Intercomparison Project Phase 6 (CMIP6) experimental design and organization. Geosci. Model Dev., 9, 19371958, https://doi.org/10.5194/gmd-9-1937-2016.

Forsythe, N., S. Blenkinsop, and H. Fowler, 2015: Exploring objective climate classification for the Himalayan arc and adjacent regions using gridded data sources. Earth Syst. Dyn., 6, 311-326, https://doi.org/10.5194/esd-6-311-2015.

Gao, Y., J. Xu, and D. Chen, 2015: Evaluation of WRF mesoscale climate simulations over the Tibetan Plateau during 19792011. J. Climate, 28, 2823-2841, https://doi.org/10.1175/JCLID-14-00300.1.

Gidden, M. J., and Coauthors, 2019: Global emissions pathways under different socioeconomic scenarios for use in CMIP6: A dataset of harmonized emissions trajectories through the end of the century. Geosci. Model Dev., 12, 1443-1475, https:// doi.org/10.5194/gmd-12-1443-2019. 
Guo, D., E. Yu, and H. Wang, 2016: Will the Tibetan Plateau warming depend on elevation in the future? J. Geophys. Res. Atmos., 121, 3969-3978, https://doi.org/10.1002/2016JD024871.

Guo, H., A. Bao, T. Chen, G. Zheng, Y. Wang, L. Jiang, and P. De Maeyer, 2021: Assessment of CMIP6 in simulating precipitation over arid Central Asia. Atmos. Res., 252, 105451, https:// doi.org/10.1016/j.atmosres.2021.105451.

Gusain, A., S. Ghosh, and S. Karmakar, 2020: Added value of CMIP6 over CMIP5 models in simulating Indian summer monsoon rainfall. Atmos. Res., 232, 104680, https://doi.org/ 10.1016/j.atmosres.2019.104680.

Han, P., X. Lin, W. Zhang, G. Wang, and Y. Wang, 2019: Projected changes of alpine grassland carbon dynamics in response to climate change and elevated $\mathrm{CO}_{2}$ concentrations under Representative Concentration Pathways (RCP) scenarios. PLOS ONE, 14, e0215261, https://doi.org/10.1371/journal.pone.0215261.

Harris, R. B., 2010: Rangeland degradation on the QinghaiTibetan plateau: A review of the evidence of its magnitude and causes. J. Arid Environ., 74 (1), 1-12, https://doi.org/ 10.1016/j.jaridenv.2009.06.014.

Immerzeel, W. W., L. P. Van Beek, and M. F. Bierkens, 2010: Climate change will affect the Asian water towers. Science, 328, 1382-1385, https://doi.org/10.1126/science.1183188.

IPCC, 2013: Climate Change 2013: The Physical Science Basis. T. F. Stocker, Eds., Cambridge University Press, 1585 pp.

— 2014: Climate Change 2014: Synthesis Report. IPCC, 151 pp.

Jacob, T., J. Wahr, W. T. Pfeffer, and S. Swenson, 2012: Recent contributions of glaciers and ice caps to sea level rise. Nature, 482, 514-518, https://doi.org/10.1038/nature10847.

Jain, S., S. K. Mishra, P. Salunke, and S. Sahany, 2019: Importance of the resolution of surface topography vis-à-vis atmospheric and surface processes in the simulation of the climate of Himalaya-Tibet highland. Climate Dyn., 52, 4735-4748, https://doi.org/10.1007/s00382-018-4411-0.

Jiao, Y., Q. You, H. Lin, and J. Min, 2016: Spatiotemporal distribution of surface temperature over the Qinghai-Tibetan Plateau from 1979 to 2012. Arid Zone Res., 33, 283-291, https://doi.org/10.13866/j.azr.2016.02.09.

Jie, W., F. Vitart, T. Wu, and X. Liu, 2017: Simulations of the Asian summer monsoon in the sub-seasonal to seasonal prediction project (S2S) database. Quart. J. Roy. Meteor. Soc., 143, 22822295, https://doi.org/10.1002/qj.3085.

Joswiak, D. R., T. Yao, G. Wu, L. Tian, and B. Xu, 2013: Ice-core evidence of westerly and monsoon moisture contributions in the central Tibetan Plateau. J. Glaciol., 59, 56-66, https:// doi.org/10.3189/2013JoG12J035.

Karthe, D., I. Abdullaev, B. Boldgiv, D. Borchardt, S. Chalov, J. Jarsjö, L. Li, and J. A. Nittrouer, 2017: Water in Central Asia: An integrated assessment for science-based management. Environ. Earth Sci., 76, 690, https://doi.org/10.1007/ s12665-017-6994-x.

Koutroulis, A. G., M. G. Grillakis, I. K. Tsanis, and L. Papadimitriou, 2016: Evaluation of precipitation and temperature simulation performance of the CMIP3 and CMIP5 historical experiments. Climate Dyn., 47, 1881-1898, https://doi.org/10.1007/s00382-0152938-x.

Kuang, X., and J. J. Jiao, 2016: Review on climate change on the Tibetan Plateau during the last half century. J. Geophys. Res. Atmos., 121, 3979-4007, https://doi.org/10.1002/2015JD024728.

Kumar, O., A. L. Ramanathan, J. Bakke, B. S. Kotlia, J. P. Shrivastava, P. Kumar, R. Sharma, and P. Kumar, 2021: Role of Indian summer monsoon and westerlies on glacier variability in the Himalaya and East Africa during Late Quaternary: Review and new data. Earth-Sci. Rev., 212, 103431, https://doi.org/ 10.1016/j.earscirev.2020.103431.

Li, P., K. Furtado, T. Zhou, H. Chen, and J. Li, 2021: Convectionpermitting modelling improves simulated precipitation over the central and eastern Tibetan Plateau. Quart. J. Roy. Meteor. Soc., 147, 341-362, https://doi.org/10.1002/qj.3921.

Li, X., L. Wang, D. Chen, K. Yang, B. Xue, and L. Sun, 2013: Nearsurface air temperature lapse rates in the mainland China during 1962-2011. J. Geophys. Res. Atmos., 118, 7505-7515, https://doi.org/10.1002/jgrd.50553.

Lin, C., D. Chen, K. Yang, and T. Ou, 2018: Impact of model resolution on simulating the water vapor transport through the central Himalayas: Implication for models' wet bias over the Tibetan Plateau. Climate Dyn., 51, 3195-3207, https://doi.org/ 10.1007/s00382-018-4074-x.

Lutz, A. F., W. W. Immerzeel, A. B. Shrestha, and M. F. P. Bierkens, 2014: Consistent increase in High Asia's runoff due to increasing glacier melt and precipitation. Nat. Climate Change, 4, 587-592, https://doi.org/10.1038/nclimate2237.

Ma, Y., Y. Zhang, D. Yang, and S. B. Farhan, 2015: Precipitation bias variability versus various gauges under different climatic conditions over the Third Pole Environment (TPE) region. Int. J. Climatol., 35, 1201-1211, https://doi.org/10.1002/joc.4045.

Maussion, F., D. Scherer, T. Mölg, E. Collier, J. Curio, and R. Finkelnburg, 2014: Precipitation seasonality and variability over the Tibetan Plateau as resolved by the High Asia Reanalysis. J. Climate, 27, 1910-1927, https://doi.org/10.1175/JCLI-D-13-00282.1.

Micklin, P., 2016: The future Aral Sea: Hope and despair. Environ. Earth Sci., 75, 844, https://doi.org/10.1007/s12665-016-5614-5.

O'Neill, B. C., and Coauthors, 2016: The Scenario Model Intercomparison Project (ScenarioMIP) for CMIP6. Geosci. Model Dev., 9, 3461-3482, https://doi.org/10.5194/gmd-9-34612016.

Palazzi, E., J. von Hardenberg, S. Terzago, and A. Provenzale, 2015: Precipitation in the Karakoram-Himalaya: A CMIP5 view. Climate Dyn., 45, 21-45, https://doi.org/10.1007/s00382-014-2341-z.

- L. Filippi, and J. von Hardenberg, 2017: Insights into elevation-dependent warming in the Tibetan Plateau-Himalayas from CMIP5 model simulations. Climate Dyn., 48, 3991-4008, https://doi.org/10.1007/s00382-016-3316-z.

Pascoe, C., B. N. Lawrence, E. Guilyardi, M. Juckes, and K. E. Taylor, 2020: Documenting numerical experiments in support of the Coupled Model Intercomparison Project Phase 6 (CMIP6). Geosci. Model Dev., 13, 2149-2167, https://doi.org/ 10.5194/gmd-13-2149-2020.

Peng, D., T. Zhou, L. Zhang, W. Zhang, and X. Chen, 2020: Observationally constrained projection of the reduced intensification of extreme climate events in Central Asia from $0.5^{\circ} \mathrm{C}$ less global warming. Climate Dyn., 54, 543-560, https://doi.org/ 10.1007/s00382-019-05014-6.

Pihl, E., and Coauthors, 2019: 10 new insights in climate science 2019. Future Earth \& The Earth League, accessed 16 March 2021, https://futureearth.org/publications/science-insights/10-newinsights-in-climate-science-2019/.

Pohlmann, H., W. A. Müller, M. Bittner, S. Hettrich, K. Modali, K. Pankatz, and J. Marotzke, 2019: Realistic quasi-biennial oscillation variability in historical and decadal hindcast simulations using CMIP6 forcing. Geophys. Res. Lett., 46, 1411814 125, https://doi.org/10.1029/2019GL084878.

Raghavan, S. V., J. Liu, N. Ngoc Son, V. Minh Tue, and S.-Y. Liong, 2018: Assessment of CMIP5 historical simulations of rainfall over Southeast Asia. Theor. Appl. Climatol., 132, 9891002, https://doi.org/10.1007/s00704-017-2111-z. 
Rahimi, S. R., C. Wu, X. Liu, and H. Brown, 2019: Exploring a variable-resolution approach for simulating regional climate over the Tibetan Plateau using VR-CESM. J. Geophys. Res. Atmos., 124, 4490-4513, https://doi.org/10.1029/2018JD028925.

RGI Consortium, 2017: Randolph Glacier Inventory-A dataset of global glacier outlines: Version 6.0: GLIMS Tech. Rep., 71 pp., https://doi.org/10.7265/N5-RGI-60.

Riahi, K., and Coauthors, 2017: The Shared Socioeconomic Pathways and their energy, land use, and greenhouse gas emissions implications: An overview. Global Environ. Change, 42, 153-168, https://doi.org/10.1016/j.gloenvcha.2016.05.009.

Rupp, D. E., J. T. Abatzoglou, K. C. Hegewisch, and P. W. Mote, 2013: Evaluation of CMIP5 20th century climate simulations for the Pacific Northwest USA. J. Geophys. Res. Atmos., 118, 10 884-10 906, https://doi.org/10.1002/jgrd.50843.

Shang, W., K. Duan, S. Li, X. Ren, and B. Huang, 2021: Simulation of the dipole pattern of summer precipitation over the Tibetan Plateau by CMIP6 models. Environ. Res. Lett., 16, 014047, https://doi.org/10.1088/1748-9326/abd0ac.

Singh, D., S. Ghosh, M. K. Roxy, and S. McDermid, 2019: Indian summer monsoon: Extreme events, historical changes, and role of anthropogenic forcings. Wiley Interdiscip. Rev.: Climate Change, 10, e571, https://doi.org/10.1002/wcc.571.

Sorg, A., B. Mosello, G. Shalpykova, A. Allan, M. Hill Clarvis, and M. Stoffel, 2014: Coping with changing water resources: The case of the Syr Darya river basin in Central Asia. Environ. Sci. Policy, 43, 68-77, https://doi.org/10.1016/j.envsci.2013.11.003.

Stouffer, R. J., V. Eyring, G. A. Meehl, S. Bony, C. Senior, B. Stevens, and K. E. Taylor, 2017: CMIP5 scientific gaps and recommendations for CMIP6. Bull. Amer. Meteor. Soc., 98, 95-105, https://doi.org/10.1175/BAMS-D-15-00013.1.

Su, F., X. Duan, D. Chen, Z. Hao, and L. Cuo, 2013: Evaluation of the global climate models in the CMIP5 over the Tibetan Plateau. J. Climate, 26, 3187-3208, https://doi.org/10.1175/ JCLI-D-12-00321.1.

—, L. Zhang, T. Ou, D. Chen, T. Yao, K. Tong, and Y. Qi, 2016: Hydrological response to future climate changes for the major upstream river basins in the Tibetan Plateau. Global Planet. Change, 136, 82-95, https://doi.org/10.1016/j.gloplacha.2015.10.012.

Tang, G., D. Long, Y. Hong, J. Gao, and W. Wan, 2018: Documentation of multifactorial relationships between precipitation and topography of the Tibetan Plateau using spaceborne precipitation radars. Remote Sens. Environ., 208, 82-96, https://doi.org/10.1016/j.rse.2018.02.007.

Wang, C., and Z. H. Wang, 2020: A network-based toolkit for evaluation and intercomparison of weather prediction and climate modeling. J. Environ. Manage., 268, 110709, https:// doi.org/10.1016/j.jenvman.2020.110709.

Wang, M., and Coauthors, 2019: Recent recovery of the boreal spring sensible heating over the Tibetan Plateau will continue in CMIP6 future projections. Environ. Res. Lett., 14, 124066, https://doi.org/10.1088/1748-9326/ab57a3.

Wei, Z., and W. Dong, 2015: Assessment of simulations of snow depth in the Qinghai-Tibetan Plateau using CMIP5 multimodels. Arct. Antarct. Alp. Res., 47, 611-625, https://doi.org/ 10.1657/AAAR0014-050.

White, C. J., T. W. Tanton, and D. W. Rycroft, 2014: The impact of climate change on the water resources of the Amu Darya basin in Central Asia. Water Resour. Manage., 28, 5267-5281, https:// doi.org/10.1007/s11269-014-0716-x.
Williams, M. W., and V. G. Konovalov, 2008: Central Asia temperature and precipitation data, 1879-2003, version 1. National Snow and Ice Data Center, accessed 16 March 2021, https://doi.org/ 10.7265/N5NK3BZ8.

Wu, G., and Coauthors, 2015: Tibetan Plateau climate dynamics: Recent research progress and outlook. Natl. Sci. Rev., 2, 100116, https://doi.org/10.1093/nsr/nwu045.

Xin, X., T. Wu, J. Zhang, J. Yao, and Y. Fang, 2020: Comparison of CMIP6 and CMIP5 simulations of precipitation in China and the East Asian summer monsoon. Int. J. Climatol., 40, 64236440, https://doi.org/10.1002/joc.6590.

Xu, X., C. Lu, X. Shi, and S. Gao, 2008: World water tower: An atmospheric perspective. Geophys. Res. Lett., 35, L20815, https://doi.org/10.1029/2008GL035867.

Yang, D. Q., and Coauthors, 2001: Compatibility evaluation of national precipitation gage measurements. J. Geophys. Res., 106, 1481-1491, https://doi.org/10.1029/2000JD900612.

Yang, K., H. Wu, J. Qin, C. Lin, W. Tang, and Y. Chen, 2014: Recent climate changes over the Tibetan Plateau and their impacts on energy and water cycle: A review. Global Planet. Change, 112, 7991, https://doi.org/10.1016/j.gloplacha.2013.12.001.

Yao, T., and Coauthors, 2012: Different glacier status with atmospheric circulations in Tibetan Plateau and surroundings. Nat. Climate Change, 2, 663-667, https://doi.org/10.1038/nclimate1580. - and Coauthors, 2013: A review of climatic controls on $\delta^{18} \mathrm{O}$ in precipitation over the Tibetan Plateau: Observations and simulations. Rev. Geophys., 51, 525-548, https://doi.org/10.1002/rog.20023.

— pan-third pole. Bull. Chinese Acad. Sci., 32, 924-931, https:// doi.org/10.16418/j.issn.1000-3045.2017.09.001.

— , and Coauthors, 2019: Recent Third Pole's rapid warming accompanies cryospheric melt and water cycle intensification and interactions between monsoon and environment: Multidisciplinary approach with observation, modeling and analysis. Bull. Amer. Meteor. Soc., 100, 423-444, https://doi.org/ 10.1175/BAMS-D-17-0057.1.

You, Q., Z. Cai, F. Wu, Z. Jiang, N. Pepin, and S. S. P. Shen, 2021: Temperature dataset of CMIP6 models over China: Evaluation, trend and uncertainty. Climate Dyn., 57, 17-35, https://doi.org/ 10.1007/s00382-021-05691-2.

Zhang, H., Y. Gao, J. Xu, Y. Xu, and Y. Jiang, 2019: Decomposition of future moisture flux changes over the Tibetan Plateau projected by global and regional climate models. J. Climate, 32, 7037-7053, https://doi.org/10.1175/JCLI-D-19-0200.1.

Zhao, D., and S. Wu, 2019: Projected changes in permafrost active layer thickness over the Qinghai-Tibet Plateau under climate change. Water Resour. Res., 55, 7860-7875, https://doi.org/ 10.1029/2019WR024969.

Zhao, Q., and Coauthors, 2019: Projecting climate change impacts on hydrological processes on the Tibetan Plateau with model calibration against the glacier inventory data and observed streamflow. J. Hydrol., 573, 60-81, https://doi.org/10.1016/ j.jhydrol.2019.03.043.

Zhu, H., Z. Jiang, J. Li, W. Li, C. Sun, and L. Li, 2020: Does CMIP6 inspire more confidence in simulating climate extremes over China? Adv. Atmos. Sci., 37, 1119-1132, https://doi.org/ 10.1007/s00376-020-9289-1.

Zhu, Y., and S. Yang, 2020: Evaluation of CMIP6 for historical temperature and precipitation over the Tibetan Plateau and its comparison with CMIP5. Adv. Climate Change Res., 11, 239251, https://doi.org/10.1016/j.accre.2020.08.001. 